\title{
Reflexiones en torno al informe para la preparación de un Estatuto Básico de Empleado Público: especial referencia a la propuesta de reducción del contenido y alcance de lo básico
}

\author{
Jorge Fondevila Antolín \\ Letrado del Gobierno de Cantabria \\ Secretario de Administración Local
}

\begin{abstract}
Sumario: I. CONSIDERACIONES INICIALES. II. APROXIMACIÓN AL CONCEPTO Y CONTENIDO DE LO BÁSICO. III. EXAMEN DEL CÁRACTER DE MUTABILIDAD O VARIABILIDAD DEL CONTENIDO MATERIAL DE LO BÁSICO. A) Posiciones Doctrinales Iniciales. B) Nuevas Propuestas Doctrinales. IV. EL CONTENIDO DE LO BÁSICO CON RELACIÓN AL ESTATUTO DE LA FUNCIÓN PÚBLICA. A) Las Primeras Reflexiones. B) Examen de últimas posiciones doctrinales. C) Conclusiones finales. V. CONSIDERACIONES SOBRE EL CONTENIDO MATERIAL DEL ESTATUTO DE LA FUNCIÓN PÚBLICA. VI. ESTATUTO DE MÍNIMOS O RENUNCIA A LA COMPETENCIA SOBRE LO BÁSICO CONSTITUCIONALMENTE RECONOCIDA. VII. BREVES REFLEXIONES SOBRE ALGUNAS DE LAS PROPUESTAS CONTENIDAS EN EL INFORME. A) La Carrera Administrativa y su necesaria regulación por el futuro Estatuto de los Empleados Públicos. B) Las Retribuciones y la Carrera Administrativa. C) La Plurianulidad en los Acuerdos Saláriales.
\end{abstract}

\section{CONSIDERACIONES INICIALES}

Tras un frenazo de varios años ha vuelto a retomarse por el Gobierno del Estado la cuestión de la elaboración del preceptivo, por exigencia constitucional del artículo 103.3 CE. en concordancia con las previsiones del artículo 149.1.18 CE, Estatuto de la Función Pública, voluntad que debe necesariamente ser bienvenida, si bien, otra cuestión es el alcance y sentido de algunos de los contenidos propuestos por la Comisión encargada de elaborar el Informe que deberá servir de sustento para la elaboración de un futuro texto articulado del Estatuto.

Así, de entrada debemos resaltar que el denominado oficialmente «Informe de la Comisión para el Estudio y preparación del Estatuto Básico del Empleado Público ${ }^{1} »$, debe recibir un merecido elogio por la profundidad del trabajo realizado, tanto en el estudio previo que permite rea-

\footnotetext{
${ }^{1}$ Véase, «Informe de la Comisión para el estudio y preparación del Estatuto Básico del Empleado Público», Colección: Estudios Goberna, INAP, Madrid 2005.
} 
lizar un diagnóstico detallado de la actual situación de las administraciones públicas, como por la propuesta, en especial, de incorporación de algunas novedades al ámbito de la Función Pública que venían siendo objeto de debate y de propuestas en los últimos años por algunos sectores de la doctrina ${ }^{2}$, y por las propias organizaciones sociales y sindicales, destacando a título de ejemplo cuestiones como la incorporación de un concepto como el del «Empleado Público», y el establecimiento de un marco jurídico para este ámbito subjetivo, igualmente las llamativas novedades y muchas de ellas realmente satisfactorias en el ámbito de los derechos sindicales, como también la incorporación de la interdicción de la opción indemnizatoria en caso de despido improcedente, y asimismo las novedades en los mecanismos de reclutamiento del personal al servicio de las administraciones públicas.

Efectivamente, lo primero que destaca de este informe es la novedad de la proposición de elaboración de un «estatuto del empleado público» y no de la «función pública» como tradicionalmente se venía considerando en anteriores proyectos y también por sectores doctrinales. A este respecto debemos anticipar nuestra opinión inicialmente favorable a esta propuesta como no podía ser de otra manera, dado lo manifestado en otros trabajos al respecto, ahora bien, no podemos coincidir en la articulación jurídico formal propuesta ya que a nuestro entender, la solución adoptada procede de las consideraciones formuladas por las posiciones doctrinales (Sánchez Morón, Palomar Olmeda), ya que, en general, el punto de partida de ambos es la realidad fáctica, es decir la presencia cuantitativamente abrumadora de personal laboral al servicio de las administraciones públicas, a través especialmente de mecanismos que buscan una pérdida de influencia del derecho Público en la Administración, en el caso de Palomar Olmeda, nos encontramos con que su propuesta se centra en el reconocimiento de un «Estatuto funcionarial», si bien, admite que contenidos del mismo pueden resultar de aplicación al resto del personal, pero lo más destacado es su propuesta de la necesidad de un «Derecho de la Función Pública», por otro lado, Sánchez Morón intenta reconducir la necesidad de una regulación conjunta de una serie de contenidos comunes del empleo público, mediante la justificación de que estos contenidos

\footnotetext{
2 Véase, las principales posiciones que han surgido en torno a ese debate A. PALOMAR OlmEDA, «Derecho de la Función Pública (Régimen Jurídico de los funcionarios públicos)», Edit. Dykinson, Madrid 2003, asimismo, M. SÁnCHEZ Morón, «Derecho de la Función Pública», Tecnos, Madrid,1997, también, la posición sostenida por J. Fondevila ANTOLIN, «Constitución y Empleo Público (Estudio y propuestas con relación a un régimen jurídico común)», Edit. Comares , Granada 2000, y por último, J. CANTERo MARTinez, «El Empleo Público: entre Estatuto Funcionarial y Contrato Laboral», Edit. Marcial Pons-Univ. Castilla-La Mancha, Madrid 2001, que como conclusión final formula la propuesta de elaboración de un Estatuto único.
} 
deben formar parte necesariamente del «Estatuto de los funcionarios públicos», recogido en el artículo 103.3 de la Constitución, dando una interpretación nueva a las previsiones constitucionales para lograr justificar la inclusión de contenidos a una figura, cual es el «Estatuto», que conforme el propio pronunciamiento del Tribunal Constitucional (STC 99/1987) esta reservada en exclusiva al ámbito funcionarial, y todo ello, por la necesidad de encontrar anclaje jurídico al hecho de la presencia de personal laboral en la administración y la existencia de modulaciones de su régimen jurídico por estar al servicio de las Administraciones e igualmente la presencia de «aproximaciones», a su entender del Derecho del Trabajo en la configuración del régimen jurídico de los funcionarios, es decir, partiendo del análisis de la realidad que configura diferentes relaciones de empleo público, no se considera oportuno su delimitación, a pesar de las graves consecuencias que en el funcionamiento de la administración esta cuestión provoca, y no solo desde la perspectiva de la actuación diaria del empleado público, sino de las dificultades de gestión de los recursos humanos por la administración con las lógicas consecuencias de ineficacia, con lo cual se produce un claro incumplimiento del principio esencial y de cierre de la organización administrativa, cual es "La Eficacia», si bien se intenta buscar un punto de conexión entre ambas legislaciones pero para ello se acude a un «vestido» que no es el adecuado para la ocasión, a nuestro entender, es decir, la transformación del «Estatuto de los Funcionarios Públicos», en un «Estatuto de los Empleados Públicos», criterio que no compartimos y no por que no estemos de acuerdo con la realidad fáctica, sino que entendemos que la cuestión debe situarse en un estadio jurídico superior (orden axiológico constitucional), como ya explicamos en otro trabajo ${ }^{3}$, de todas formas de una manera breve podemos señalar:

En primer lugar, estamos de acuerdo en la apreciación que de la realidad efectúan los anteriores autores, si bien, entendemos que ese proceso emprendido por la Administración no respeta las previsiones constitucionales, y especialmente si examinamos los procesos de «huida del derecho administrativo», sin olvidar que la Constitución ha optado claramente por una relación de empleo funcionarial, con carácter general y solo para el resto de los supuestos es admisible la relación laboral, en segundo lugar, también coincidimos en entender que la configuración de ciertos contenidos del régimen jurídico de los empleados públicos no responden a la clásica y estricta separación entre funcionarios y laborales desde la perspectiva más ortodoxa de su concepción, por ello, hay que buscar cuáles son

3 Véase, J. Fondevila Antolin, op. cit. «Constitución y Empleo Público ...», p. 165 y ss. 
las razones que independientemente de las decisiones puntuales del legislador ordinario amparan la aparición de este conjunto de contenidos que por la doctrina han sido denominados como «modulaciones» o «aproximaciones» en la configuración del régimen jurídico de las relaciones de empleo público, y estas las encontramos en la búsqueda de un «elemento común» que se encuentre presente en todos y cada uno de los contenidos comunes a incorporar al régimen jurídico de la totalidad de los empleados públicos, este elemento se encuentra en la directa proyección del orden axiológico constitucional (1.1. y 10.1 CE) de tal manera que todos los aspectos a incorporar al régimen jurídico del empleo público comparten el que su razón de ser se encuentra en los valores y principios constitucionales, y son estos los que se constituyen en el parámetro o medida que nos va a permitir decidir su inclusión dentro de la normativa común del empleo público, de tal manera que no estamos ante ningún proceso de «osmosis», es decir, que no nos encontramos ante instituciones de una $\mathrm{u}$ otra rama jurídica sino ante instituciones jurídicas directamente justificadas en el orden constitucional originario.

Por todo ello, propusimos ${ }^{4}$ y seguimos manteniendo el mismo criterio, de elaboración de un conjunto normativo común para todo el empleo público que no sea fruto de ningún proceso de «funcionarización o laboralización», sino que su justificación se encuentra en el orden axiológico constitucional y cuya denominación podría ser la de «Normas Marco del Empleo Público», lógicamente al aparecer este nuevo ámbito jurídico, el mismo debe ser objeto de una ordenación conforme a un criterio jerárquico, con independencia de los correspondientes desarrollos reglamentarios o convencionales que presenten.

De esta forma, estarían en primer lugar las que hemos denominado «Normas Marco del Empleo Público», que recogerían el conjunto de los contenidos comunes por exigencia del orden axiológico constitucional y que tendrían el carácter de «ius cogens» sobre la totalidad del régimen jurídico común del empleo público; en segundo lugar estaríamos en presencia del que sería propiamente "Estatuto Básico de los Funcionarios Públicos», de conformidad con el artículo 103.3 de la Constitución para las relaciones de naturaleza jurídico funcionarial y paralelamente con este, el personal con relación laboral sometería el resto del contenido de su régimen jurídico al «Estatuto de los Trabajadores», al amparo del articulo 35.2 de la Constitución, si bien, con relación al personal funcionario que tuviera como único punto de referencia y regulación de su régimen

4 Véase, Ibid., p. 173. 
jurídico el «Estatuto Básico» conforme al artículo 103.3, se abre la posibilidad de un desarrollo de su contenido, a través del correspondiente regulación reglamentaria y especialmente de los «Acuerdos y Pactos» adoptados al amparo de las previsiones de la Ley 9/1987, en aquel conjunto de materias disponibles a la negociación; y, en tercer lugar, nos encontraríamos con los «Estatutos Específicos», es decir con referencia a aquellos ámbitos donde sus peculiaridades hacen necesaria una especial adecuación de su régimen jurídico (Sanidad, Educación, Investigación, etc.) sin olvidar las posibilidades de desarrollo (Pactos, Acuerdos) como en el caso del «Estatuto Básico»; y en el ámbito del personal laboral nos encontraríamos en la esfera de los «Convenios Colectivos».

Retomando la cuestión debemos concluir al respecto afirmando que si bien nos alegramos de que el documento reconozca lo esencial de las tesis favorables a una visión más amplia del «empleo público», seguimos pensando que sería más respetuoso, en estricto sentido jurídico, con la Constitución el que se hubiera propuesto la elaboración de dos marcos jurídicos diferenciados, uno común al conjunto de las relaciones jurídico laborales y funcionariales y otro totalmente específico, en el sentido del artículo 103.3 CE (Estatuto de la Función Pública).

Por otro lado, de forma breve necesariamente, pues el objeto de este trabajo no es en ningún caso una contestación o valoración integral al citado Informe, queremos destacar otros aspectos novedosos y que merecen una valoración favorable, así, en cuanto al Capitulo XV (Representación, participación y negociación colectiva de los empleados públicos), y, en concreto, el desarrollo y configuración de los órganos de representación del personal funcionario las propuestas son claramente continuistas, es en el área de desarrollo del derecho de negociación donde se incorporan importantes novedades, de forma que nos encontramos con la propuesta de reconocimiento expreso de una serie de principios informadores de la negociación, en concreto, legalidad, cobertura presupuestaria, obligatoriedad de la negociación, buena fe negocial, lealtad y colaboración y el de publicidad, lo que supone la incorporación de un marco jurídico que dirigirá el desarrollo de la negociación, y que a su vez es proyección del contenido intrínseco del derecho de negociación. A este respecto también se propone el reconocimiento de legitimación negocial a las asociaciones de municipios, lo que supone un gran avance con relación a la situación en la que se encuentra actualmente la Administración Local, más dudosa es la propuesta de atribución de capacidad negociadora a las Juntas de Personal y Delegados en el ámbito local, y más, si tenemos en cuenta la propuesta anterior referida a ámbitos generales como pueden ser las citadas asociaciones de municipios. 
También, merece una acogida favorable la propuesta de incorporación al proceso negociador de una libertad de establecimiento de Mesas sectoriales de negociación, así como, la creación de una Mesa General de Negociación común a todas las Administraciones Públicas, para todos los asuntos que necesariamente incidan sobre la totalidad del empleo público $\mathrm{y}$, asimismo, la posibilidad de que esta unidad admita en su seno a representantes de otras administraciones, bien, a título de observador o como titular por el interés de negociar cuestiones en las que estas concretas administraciones consideren adecuado mantener una posición común a todas ellas; cuestión más discutible es el listado de materias que deben ser objeto de negociación y consulta, si bien, consideramos que esta materia dado el sentido de este trabajo merece un tratamiento más amplio y detallado que escapa a la naturaleza del mismo. También debe ser acogida de forma satisfactoria la propuesta de establecimiento de unidades y mecanismos de negociación conjunta para el personal laboral y funcionario.

Otra propuesta a destacar de forma favorable es la determinación de que los Acuerdos y Pactos que suscriban las Administraciones con las Organizaciones Sindicales requerirán de la mayoría de los miembros de la unidad negociadora, que supera afortunadamente la grave situación actual donde como muy acertadamente señala el informe un sindicato totalmente minoritario e incluso sin representación en un sector determinado puede suscribir un acuerdo y desplegar él mismo efectos «erga omnes», y también es importante el reconocimiento de la posibilidad de adhesión a Acuerdos previamente adoptados por otra administración.

Opinión diferente nos merece la propuesta de regulación unilateral de las condiciones de trabajo cuando un pacto haya finalizado su vigencia y tras el transcurso de seis meses no se haya alcanzado acuerdo, dado que en esta situación partimos de un marco jurídico anterior, es decir, no existe vacío legal alguno y si bien, razones de interés público pueden justificar la necesidad de una regulación unilateral de las condiciones, esa justificación debería ser exigible y delimitada normativamente y no dejarla como una cláusula abierta; de todas formas la valoración tiene que ser necesariamente favorable al detallado y preciso trabajo desarrollado en este punto por la Comisión.

En cuanto a la materia de acceso al empleo público estudiada en el Capitulo VIII, también tenemos que mostrar nuestra favorable consideración a la misma, al incorporar importantes propuestas sobre los sistemas y procedimientos de selección, así, la prohibición absoluta de las pruebas restringidas, también la incorporación de un espectro más amplio de pruebas de capacidad, así como de otros sistemas de valoración añadidos 
y el establecimiento como excepción y necesariamente justificada de la sustitución de una prueba de capacidad por una mera valoración de méritos y la incorporación de mecanismos novedosos en el caso de reclutamientos masivos. Por otro lado, la exigencia de que la composición de los órganos de selección debe ser estrictamente técnica tiene que ser acogida favorablemente, y también la creación de órganos independientes de garantía.

Asimismo, tenemos que mostrar nuestro total apoyo a la propuesta de interdicción de la posibilidad de opción indemnizatoria en caso de despido calificado judicialmente como improcedente en las relaciones jurídico laborales, ya que esta consideración fue estudiada y propuesta por nuestra parte en otro trabajo ${ }^{5}$ anterior a este informe y al cual nos remitimos.

Por último, tras haber observado como este Informe debe ser valorado muy positivamente, ello no es óbice de que también exista a nuestro entender una laguna en el mismo, o más bien, un problema de concepción global y de gran trascendencia, y este no es otro que la manifiesta propuesta de reducción del alcance y contenido de lo básico a regular por un futuro Estatuto del Empleado Público, ya que la Comisión manifiesta expresamente en su informe que su propuesta de Estatuto es de «mínimos», nosotros iríamos un poco más allá, diríamos de renuncia al contenido y alcance actual de lo básico en la materia de empleo público, y ello, por razones no fundamentalmente jurídicas, entendiendo que estas no suponen impedimento alguno a la reducción del contenido del futuro Estatuto, y es aquí donde tenemos que disentir, pues como expondremos en la parte fundamental de este trabajo sí existen razones jurídico constitucionales para que esta premisa de trabajo del informe no pueda ser admitida.

Efectivamente, la cuestión tiene enorme trascendencia pues esta decisión previa incide directamente en la clave de bóveda de todo sistema de función pública, que no es otra que las materias referidas a la carrera administrativa y por directa conexión con la misma el sistema de retribuciones, ya que de una adecuada lectura del texto del informe se puede observar como existe una renuncia expresa a que por parte del legislador básico se regule mención alguna sobre la carrera, y ello, con independencia de que la Comisión si examina este tema pero no con un alcance general sino como una recomendación al Estado para su propia organización, debiendo manifestar nuestra total adhesión a la propuesta formulada sobre la instauración de una "carrera administrativa horizontal», que nos parece una de las aportaciones más correctas y adecuadas del informe, así pues, procede-

5 Véase, J. Fondevila Antolin, op. cit. «Constitución y Empleo Público ...», p. 272 y ss. 
mos a continuación a exponer nuestra posición con respecto a este tema esencial y que condiciona la concepción esencial del futuro Estatuto.

\section{APROXIMACIÓN AL CONCEPTO Y CONTENIDO DE LO BÁSICO}

Para una correcta comprensión de las cuestiones sobre las que deseamos reflexionar, en especial sobre el alcance del contenido jurídico material del futuro Estatuto de la función pública, es preciso a nuestro entender seguir un proceso ordenado de exposición, debiendo comenzar lógicamente por un repaso necesariamente breve, dado el sobrado conocimiento que cualquier lector tendrá sobre la naturaleza y alcance de lo «Básico» en nuestro orden jurídico constitucional.

En primer lugar, como cuestión metodológica indicamos que nuestra exposición se centrara en el examen del ámbito jurídico material, dado que este aspecto es el que realmente tiene una trascendencia sobre el objeto de este trabajo, así, recordemos lo que ya de forma muy temprana declaró nuestro Tribunal Constitucional sobre el carácter material de la noción de bases, normas básicas y legislación básica, destacando lo declarado en la STC 32/1981, que podemos resumir de la siguiente forma:

a) La noción de bases o de normas básicas ha de ser entendida como noción material y, en consecuencia, esos principios o criterios básicos, estén o no formulados como tales, son los que racionalmente se deducen de la legislación vigente.

b) Las Cortes Generales deben establecer qué es lo que haya de entenderse por básico y, en caso necesario, será el propio Tribunal Constitucional el competente para decidirlo con carácter definitivo, en su calidad de intérprete supremo de la Constitución (Art. 1 LOTC).

Ahora bien, la segunda cuestión es la delimitación del contenido de lo básico, tema importante en el presente trabajo, y así podemos constatar que si lo básico es una noción material, cuya determinación concreta queda remitida, además al momento del ejercicio de la potestad legislativa, su misma extensión y, por lo tanto, sus límites, se han ofrecido siempre problemáticos dado que los mismos con carácter general han respondido siempre a una configuración casuística ${ }^{6}$.

\footnotetext{
${ }^{6}$ Véase, Conde i CASTEJon, J. «La Conflictivitat Competencial - El Concepte de Bases», Edit. Institut d'Estudis Autonómics, Barcelona, 1992, pp. 7 y ss. y en el mismo sentido J. JIMÉNEZ CAMPO, «Legislación Básica», Voz en Enciclopedia Jurídica Básica-Vol. II , Edit. Civitas- Madrid, pp. 3933 y ss.
} 
Así, dos son los criterios fundamentales que de forma pacífica son actualmente reconocidos tanto por la doctrina científica ${ }^{7}$ como por el propio Tribunal Constitucional, para la delimitación y precisión del concepto «básico», en concreto:

1) Criterio Positivo: que considera que las bases no son sino la traducción normativa de los principios de unidad y de interés general nacional, es decir, las bases se identifican con una regulación mínima en todo el territorio nacional de una materia o sector de la realidad.

2) Criterio Negativo: según el cual la regulación básica no puede llegar a tener una densidad tal que anule cualquier opción de regulación peculiar de desarrollo, es decir, una política legislativa propia por parte de la Comunidad Autónoma, de forma que las bases no pueden suponer en ningún caso una ordenación agotadora de la materia, siendo por ello, susceptible de diferentes regulaciones en tanto no se opongan o contradigan las previsiones de las bases.

Estos criterios y, por tanto, su propia doctrina aparece recogida en lo esencial por las SsTC 32/1981, 1/1982, 80/1988, 147/1991, 172/1996, 197/1996, 37/1997 y 103/1997, destacando en especial las siguientes declaraciones:

- STC 147/1991: «la definición de las bases, en el ámbito de la legislación compartida, tiene por objeto crear un marco normativo unitario, de aplicación a todo el territorio nacional, dentro del cual las Comunidades Autónomas dispongan de un margen de actuación que les permita, mediante la competencia de desarrollo legislativo, establecer los ordenamientos complementarios que satisfagan sus peculiares intereses; por ello, en principio, debe entenderse que excede de lo básico toda aquella ordenación que, por su minuciosidad y detalle, no deja espacio alguno a la competencia autonómica de desarrollo legislativo, produciéndose en tal caso, por regla general un resultado de vulneración competencial que priva a lo presentado como básico de su condición de tal».

\footnotetext{
7 Véase, VV.AA. la obra «Normativa Básica en el Ordenamiento Jurídico Español», Edit. MAP, Madrid, 1990, también J.A. SANTAMARÍA PAStoR, «Fundamentos de Derecho Administrativo I», Edit. Centro de estudios Ramón Areces, Madrid, 1988, pp. 592 y ss. además E. Álvarez CondE, «Curso de Derecho Constitucional» Vol. II, Edit. Tecnos, Madrid, 1997, pp. 434 y ss., y asimismo, J. Tornos Mas, en la obra VV.AA. «El Sistema Jurídico de las Comunidades Autónomas», Edit. Tecnos, Madrid, 1995, pp. 143 y ss., además, E. GARCíA DE ENTERRRIA, «Estudios sobre Autonomías Territoriales», Edit. Civitas, Madrid, 1985, pp. 305 y ss., y por último, I. Del GuAYo CASTIELLA, en la obra VV.AA. «Curso de Derecho Público de las Comunidades Autónomas» Edit. MAPMontecorvo, Madrid,2003 , pp. 427 y ss.
} 
- STC 172/1996: «...el concepto de lo básico... por una parte y desde una perspectiva constitucional «consiste en el común denominador para todos en un sector determinado, pero sin olvidar, en su dimensión intelectual, el carácter nuclear inherente al concepto». Incorpora, pues, la acepción de lo fenoménico o circunstancial, cuya finalidad no es otra sino asegurar, en aras de intereses generales superiores a los de las Comunidades Autónomas, en común denominador normativo..»

- STC 103/1997: « ....una norma merece tal calificativo ( de básica) cuando garantiza en todo el Estado un común denominador normativo dirigido a asegurar, de manera unitaria y en condiciones de igualdad, los intereses generales; regulación normativa uniforme que, no obstante, debe permitir que cada Comunidad Autónoma introduzca, en persecución de sus propios intereses, las peculiaridades que estime pertinentes dentro del marco competencial que en la materia dibuje el bloque de constitucionalidad..».

De forma complementaria también conviene precisar que la regulación básica, aun siendo una noción material y constituyendo un mínimo unitario, ni requiere que la materia sobre la que opere integre la totalidad de un sector de la realidad, ni es preciso que sea igual o uniforme para todas las Comunidades Autónomas, por lo que no se confunde con las condiciones básicas para la igualdad en el ejercicio de los derechos y el cumplimiento de los deberes constitucionales de los que habla el artículo 149.1.1. C.E. (SsTC 76/1983, 87/1987, 152/1988, 150/1990 y 147/1991).

A lo anteriormente expuesto debemos añadir el examen de la forma en que se puede concretar el contenido material de las bases o de lo básico conforme la doctrina dictada por el Tribunal Constitucional y siguiendo a este respecto a TORNOS MAS ${ }^{8}$, se puede hablar de tres concepciones:

a) Una visión es la que entiende la legislación básica como norma de principios dictada para garantizar el trato unitario de todo un ámbito material, lo que supone a la vez otorgar un amplio margen de libertad para el desarrollo normativo a las comunidades autónomas y de esta manera manifestar sus propias opciones legislativas (SsTC $1 / 1982,49$ y $227 / 1988$ y 147/1991).

b) Otra opción es la que permite al legislador estatal normar de forma uniforme pero acudiendo para ello incluso a actos de ejecución (ley, reglamento y a veces acto administrativo), es decir, esta opción

\footnotetext{
${ }^{8}$ Véase, J. ToRnos Mas, VV.AA. en la obra «El Funcionamiento del Estado Autonómico», el artículo «Sistema de Distribución de Competencias», pp. 158 y ss.
} 
supone que el estado defina políticas y determine su aplicación, apareciendo de esta manera el concepto de «norma directriz» (SsTC 96/1984 y 147/1991).

c) Por último, se produce una mayor extensión de lo básico de manera que esta alcanza a todo un sector material, de forma que la misma sea regulada exclusivamente por la legislación estatal admitiendo incluso la intervención ejecutiva del Estado. Esta posición que como manifiesta el autor es claramente minoritaria siendo su mejor exponente las SsTC 179/1985 y 147/1991.

\section{EXAMEN DEL CARÁCTER DE MUTABILIDAD O VARIABILIADAD DEL CONTENIDO MATERIAL DE LO BASICO}

Tras examinar en el anterior apartado las posiciones tanto doctrinales como de la Jurisprudencia del Tribunal Constitucional sobre el concepto y alcance, al menos inicial, del concepto de bases o de lo básico, procede reflexionar en este momento sobre una cuestión clave a la hora de analizar adecuadamente el problema indicado en la introducción al presente trabajo, es decir, la reducción del contenido actualmente consolidado de lo básico en la configuración del futuro Estatuto de los Empleados Públicos.

\section{A) Posiciones Doctrinales Iniciales:}

Así, debemos comenzar por el repaso al excelente trabajo del desaparecido GARCÍA MORILLO ${ }^{9}$, que a su vez recoge en su trabajo los criterios ya prematuramente avanzados por LÓPEZ GUERRA ${ }^{10}$ sobre la naturaleza variable de lo básico, así, de manera inicial reitera lo ya expuesto en nuestro apartado anterior, en el sentido de que lo básico se constituye en el eje de la delimitación material de la intensidad o capacidad con que las Comunidades Autónomas pueden configurar sus políticas o desarrollar sus competencias ${ }^{11}$. El citado autor plantea como hipótesis básica de su trabajo la

\footnotetext{
9 Véase, J. García Morillo, «La versatilidad de lo básico», Revista de Administración Pública, n. ${ }^{\circ}$ 139 , pp. 125 y ss.

10 Véase, L. LóPez Guerra, «El Modelo Autonómico», Autonomies RCDP, n. ${ }^{\circ}$ 20, 1995, e igualmente «Conflictos Competenciales, interés general y decisión política», Revista del Centro de Estudios Constitucionales, n. ${ }^{\circ} 1$.

11 En este sentido destacamos la posición del tristemente desaparecido Tomás y Valiente al manifestar que lo básico supone «un efecto delimitador de las competencias, aunque solo sea en sentido negativo», véase «El reparto competencial en la Jurisprudencia del Tribunal Constitucional», Edit.
} 
duda sobre la posibilidad de que por parte del legislador estatal una vez definido el ámbito variable de lo básico, es decir, ejercida la libertad política de elección de un determinado alcance del contenido material de lo básico, este pueda posteriormente proceder a una nueva regulación, o bien, se encuentre vinculado definitivamente por su decisión inicial, de forma que como señala GARCÍA MORILLO ${ }^{12}$ «lo básico gozaría, puesto que ha sido definido como tal, de una cierta rigidez material: lo que ya ha sido catalogado como básico no podría dejar de serlo, y lo que no ha sido inicialmente definido como básico no podría, más tarde, serlo». Dicho lo anterior, la respuesta que nos ofrece a esta cuestión es en principio negativa y ello, por tres razones: En primer lugar, porque la Constitución no reconoce de forma expresa el concepto de inalterabilidad de lo básico, en segundo lugar, la modificación de la realidad política puede inducir a modificar el alcance de lo previamente definido como básico y en tercer lugar, porque la posibilidad de modificación es competencia del legislador o gestor democrático que en su propia condición de organización democráticamente representativa o institucional-burocrática ${ }^{13}$ como lógica consecuencia del principio constitucional «Democrático».

Ahora bien, también debe tenerse en cuenta conforme indica el citado autor que la definición de lo que es básico o no, es un ámbito cerrado sobre las materias consideradas básicas y aunque exista un margen discrecional de decisión política, este nunca podrá superar o alterar ese límite, pues lo que no podría admitirse es que el legislador básico modificase sin límite alguno sus criterios sobre lo básico ampliando o reduciendo el ámbito del mismo, si bien, como después apreciaremos con más detalle uno de los problemas claves es la consideración generalizada de que la fijación de este límite es casuística ${ }^{14}$. Continúa el citado autor señalando que dado que debe entenderse que lo básico es alterable aunque sus límites no sean claros no puede hablarse de una rigidez material de lo básico en sentido absoluto, pero sí en un sentido relativo, y ello, por cuanto de lo que no existe duda es que el legislador estatal ha de ceñirse a lo básico en su decisión, de manera que incorporara al mundo jurídico una propia defi-

Tecnos, Madrid, 1988, p. 108., criterio que ya había avanzado en la obra «Tribunales Constitucionales Europeos y Autonomías Territoriales», Edit. Centro de Estudios Constitucionales, Madrid, 1985 , pp. 190 y ss.

12 Véase, J. García Morillo, op. cit. «La versatilidad de .......», p. 127.

13 Véase, L. PARejo Alfonso, «Administración y Función Publica», Documentación Administrativa n. 243 , pp. 76 y 77.

${ }^{14}$ L. LÓPEZ GuERRA, op. cit. «Conflictos Competenciales, interés general y .....», p. 88 y ss., en el mismo sentido también J. JIMÉNEZ CAMPO, «Legislación Básica», Voz en Enciclopedia Jurídica Básica -Vol. II , Edit. Civitas- Madrid, pp. 3933 y ss. 
nición de lo básico o lo que es lo mismo delimita su propia competencia sobre lo básico, lo que no significa que esta debe ser aceptada dado que cualquier Comunidad Autónoma podrá solicitar su revisión por parte del Tribunal Constitucional. A todo lo anterior debe añadirse que esa actuación provoca la aparición de una clara consecuencia, que no es otra que la necesidad que tendría el legislador básico de justificar, por entender no agotado el ámbito de lo básico, una nueva redacción de este que supusiera una ampliación de lo previamente definido, por ello el autor sostiene la existencia de una «cierta rigidez material de lo básico, al menos en lo que a la posible expansión de lo básico se refiere, porque el legislador que en un momento dado reguló una materia delimitó al hacerlo-siquiera fuese temporalmente- el campo de lo básico, y simultáneamente excluyó de ese campo a todo lo no catalogado como tal ${ }^{15}$, además no debe olvidarse asimismo que para el autor la actuación legislativa básica termina integrada en el bloque de constitucionalidad y por ello, esa delimitación previa de lo básico será utilizable como parámetro de constitucionalidad.

Por último, procede el citado trabajo al estudio de las situaciones de consolidación de la legislación básica de forma que esta pueda ser definitiva, el primer supuesto sería el caso de que las CC.AA. acepten como básico lo legislado en ese momento lo que supone hasta cierto punto, a su entender, la inadmisibilidad de futuras regulaciones ampliatorias; en segundo lugar, estaría el supuesto de pronunciamiento expreso del Tribunal Constitucional de manera que aquí estaríamos en presencia de una delimitación definitiva. Por otro lado, continuando con la actuación de ese Alto Tribunal, reclama este autor el establecimiento de parámetros de definición del contenido material de lo básico, ajenos a las determinaciones casuísticas dominantes en la mayoría de los casos actuales, si bien, entiende también que existen algunos supuestos donde puede afirmarse que existen parámetros generales reconocidos por el propio Tribunal Constitucional, este concreto punto esta siendo planteada recientemente bajo el concepto de «cánones constitucionales» por VELASCO CABALLERO ${ }^{16}$, será precisamente la estabilidad de estos parámetros de definición del alcance de lo básico que nos haya aportado el Tribunal Constitucional un elemento básico para el desarrollo de nuestro sistema autonómico y en especial para que los operadores democráticos en las tomas de decisiones al respecto se encuentren plenamente amparadas en el marco constitucional, pero esta consecuencia tiene una contrapartida, y esta es, no la exi-

\footnotetext{
15 Véase, J. García Morillo, op. cit. «La versatilidad de lo ....», p. 132.

16 Véase, F. Velasco CABALlero, «Organización Territorial y Régimen Local en la reforma del Estatuto de Cataluña: limites constitucionales», pp. 286 y ss.
} 
gencia al Tribunal Constitucional de no poder modificar o modular sus criterios lógicamente, pero si el hecho de que toda modulación o modificación de criterios debe ser manifiestamente justificada. Sobre lo expuesto por el autor, con independencia de que posteriormente volveremos sobre algunos de sus postulados, llama la atención la falta de examen de la posibilidad de modificación de lo básico pero en un sentido inverso, es decir, de renuncia del legislador básico al contenido material ya regulado previamente y aceptado por el Tribunal Constitucional, siendo esta cuestión clave a nuestro entender en el actual momento de debate sobre un futuro Estatuto de los Empleados Públicos.

\section{B) Nuevas Propuestas Doctrinales:}

En directa relación con lo anteriormente estudiado aparece en el debate una nueva visión en torno a los límites constitucionales de las reformas estatutarias conectado todo ello, con la limitación o reducción del alcance del contenido material de lo básico, este planteamiento ha tenido su principal escaparate en el estudio previo elaborado en el año 2003 por un importante grupo académico con relación a la posible modificación del Estatuto de Autonomía de Cataluña ${ }^{17}$, y entendiendo que su contenido puede resultar, aunque de forma indirecta, muy interesante dado el objeto principal de este trabajo, nos provoca la necesidad de que examinemos de forma adecuada sus planteamientos.

En primer lugar, el citado informe realiza un examen sobre lo que se considera por sus autores un importante problema en la actual situación con relación a la configuración estatutaria de las competencias, entendiendo que los estatutos utilizan unas cláusulas generales que tienen su correlato con las previsiones constitucionales de reparto competencial, y así consideran que en este punto surge un problema de indeterminación que ha sido fuente de permanentes conflictos competenciales, proponiendo como remedio a la cuestión una mayor precisión sobre el alcance y contenido de las competencias, por ello, se reclama por los citados autores otras fórmulas de reparto donde los Estatutos pasen a desempeñar un papel más importante y determinante en la distribución competencial, y ello, al amparo de las previsiones del artículo 147 de la C.E. que atribuye a los Estatutos la función de determinar las competencias asumidas dentro del «marco» de la Constitución, y es precisamente este último térmi-

\footnotetext{
17 Nos estamos refiriendo al «Estudio sobre la Reforma del Estatuto» Julio 2003, elaborado por el Instituto de Estudios Autonómicos, formando parte de la Comisión Académica los siguientes Profesores: Enoch Alberti, Enric Argullol, Joaquim Ferret y Carles Viver.
} 
REFLEXIONES EN TORNO AL INFORME PARA LA PREPARACIÓN DE UN ESTATUTO BÁSICO DEL EMPLEADO PÚBLICO...

no el que sirve de soporte al informe para afirmar que una «valoración conjunta de los artículos 149.1 y 147 CE permite otorgar al Estatuto una función constitucional de precisión competencial, que no implica necesariamente la utilización de unas cláusulas genéricas e indeterminadas sobre el alcance y el contenido de las competencias que asume la Comunidad Autónoma» ${ }^{18}$. Desde esta perspectiva entienden que el artículo 149.1 puede tener otras lecturas diferentes a las actuales recomendando como alternativa una mejor y más precisa definición del alcance y contenido de los títulos competenciales, ahora bien, si este planteamiento no presenta demasiadas complejidades en su análisis inicial, la cuestión se complica al incorporar el nuevo planteamiento de considerar al Estatuto como un instrumento modulador del alcance de las competencias estata$\operatorname{les}^{19}$, y a partir de aquí nos interesa especialmente sus consideraciones dada su directa influencia en el objeto central de este trabajo, así, se afirma que los Estatutos pueden modular el alcance de las competencias estatales que quedan obligadas a respetar las especialidades derivadas de las previsiones de los propios estatutos ${ }^{20}$.

Asimismo, resaltan los autores la existencia de unos límites competenciales no derivados precisamente de la propia Constitución sino de la propia regulación estatutaria, lo cual es predicable del resto de los estatutos actualmente vigentes, y en concreto se ofrece como ejemplo las remisiones de los propios estatutos al desarrollo de unas competencias «en los términos» de la legislación básica del Estado, entendiendo que esta previsión supone un claro efecto restrictivo del potencial competencial autonómico $^{21}$, proponiendo como medida para superar esta situación la transformación de estas remisiones, de forma que se declaren las competencias como «exclusivas» de la comunidad autónoma, y ello, con la finalidad de poder reclamar en estos casos la doctrina del Tribunal Constitucional surgida al amparo de su STC 22/1999, donde el Alto Tribunal formula unas consecuencias jurídicas diferenciadas en función de que la competencia autonómica sea calificada como "exclusiva» o bien, como de "desarrollo legislativo», entendiendo, en primer lugar, que cuándo estamos en presencia de una competencia calificada formalmente por el estatuto como «exclusiva», las bases estatales actúan esencialmente como límite externo

\footnotetext{
18 Véase, op. cit. «Estudio sobre ....», p. 71 (versión en castellano).

19 Véase, en el mismo sentido C. VIVER PI-SUYER, «Los límites constitucionales de las Reformas Estatutarias», en Artículo de Opinión en el Periódico «EL PAIS», de fecha 6 de mayo de 2005.

20 Véase, F. Velasco CABAllero, op. cit. «Organización Territorial y Régimen.......», pp. 295.

21 En este sentido se ha pronunciado M. CARriLlo, en su intervención de fecha 30 de Junio de 2004 ante la «Comisión Especial sobre Autogobierno» del Parlamento del País Vasco.
} 
de esta competencia, en cambio, en segundo lugar, cuándo la competencia autonómica asume el carácter de «desarrollo legislativo», las bases estatales pueden actuar de forma que estas dirijan y orienten el ejercicio de la competencia autonómica, proponiendo el informe la reconducción de todas sus competencias al ámbito de la exclusividad, ahora bien, avanzando una consideración posterior queremos llamar la atención sobre este punto ya que la actual configuración constitucional-autonómica sobre la Función Pública se encuentra enmarcada en el ámbito del desarrollo legislativo, por lo que nos remitimos de forma obvia a las consideraciones del Tribunal Constitucional anteriormente señaladas y las lógicas consecuencias que sobre la elaboración de un Estatuto de los Empleados Públicos se generan.

Continúa el informe destacando que la actual evolución del concepto de lo básico ha provocado un vaciamiento competencial de las comunidades autónomas, dado el alto grado de detalle y precisión reguladora de las leyes básicas, proponiendo como alternativa inicial la consideración de las bases como normas estrictamente de «principios y no autosuficientes», que necesitarían de un posterior desarrollo por la ley autonómica para desplegar su total efectividad jurídico material, ahora bien, y esto es determinante, los propios autores reconocen que «sin una reforma de la propia Constitución sería dificil concretar una alternativa como la expuesta» ${ }^{22}$; ahora bien, ante esta situación se formula una consideración en el informe sobre la posibilidad de que se proceda una modificación estatutaria que reclame para el conjunto de las competencias autonómicas afectadas la consideración de exclusividad y como consecuencia de ello, reclamar la aplicación de la doctrina del Tribunal Constitucional anteriormente referida.

Por último, el informe examina el papel que desempeñan las previsiones del artículo 149.1.1 CE en la actual reparto competencial, afirmando que existe una extensión inadecuada y excesiva del título competencial derivado de las previsiones del citado precepto constitucional, ahora bien, el mismo reconoce que en esta cuestión no es posible discriminar entre aspectos competenciales y los que no lo son, ya que el artículo 149.1.1. debe ser considerado una regla competencial en si misma, añadiendo también la gran incidencia horizontal o transversal que tiene este título sobre cualquier materia vinculada a un derecho fundamental, reconociendo también en este caso que una solución definitiva a esta cuestión desde el punto de vista autonómico «debería de pasar por reconsiderar la propia existencia de la competencia del artículo 149.1.1.», para continuar seña-

22 Véase, op. cit. «Estudio sobre ....», p. 80 (versión en castellano). 
lando que «en el escenario de una reforma estatutaria se hace dificil con-

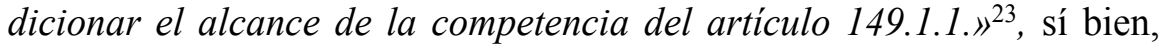
también debemos señalar los esfuerzos del informe por buscar alguna alternativa a esta conclusión centrando la misma en el pronunciamiento de la STC 173/1998, pero que entendemos que no supone otra cosa que una respuesta puntual y excepcional de la que no se ha producido continuidad alguna por parte de ese Alto Tribunal, tesis que queda confirmada al proponer finalmente el propio informe como solución definitiva la modificación constitucional del citado precepto.

\section{EL CONTENIDO DE LO BÁSICO CON RELACIÓN AL ESTATUTO DE LA FUNCIÓN PÚBLICA}

Tras examinar en los apartados anteriores la situación general tanto para la doctrina como para la Jurisprudencia Constitucional de la configuración del sentido de lo básico como de la posibilidad de mutabilidad o variabilidad del contenido del mismo, procede dar un paso más, y este no puede ser otro que el examen de la actual situación y alcance de lo básico en el ámbito específico de la Función Pública.

\section{A) Las Primeras Reflexiones:}

1.- Podemos comenzar nuestro estudio con FIGUERA I LLUCH ${ }^{24}$, que destaca que del artículo 149.1.18 CE se deduce una doble competencia estatal sobre el ámbito material de la Función Pública, alcanzando ésta dos aspectos fundamentales:

a) Competencia estatal para la regulación de la relación de servicio que forma parte indiscutible del régimen estatutario.

b) Competencia para regular los aspectos esenciales de la organización burocrática y que forma parte necesaria del régimen jurídico de la administración, y ello, de conformidad con lo manifestado por el Tribunal Constitucional en su STC 76/1983 (Fdo, Jco. 38).

Entendiendo la autora que con fundamento en el artículo $103 \mathrm{CE}$, debe ser admitida la existencia de una opción por «régimen estatuario» para el

\footnotetext{
23 Véase, op. cit. «Estudio sobre ....», p. 84 (versión en castellano).

24 Véase, M. Figuera I M. Lluch, «La Conflictivitat Competencial - El Régim Jurídic de 1'Administració», Edit. Institut d'Estudis Autonómics, Barcelona, 1992, pp. 33 y ss.
} 
personal al servicio de las administraciones públicas como elemento esencial del concepto jurídico de la organización administrativa, siendo competencia estatal su fijación al igual que el resto de las bases, apoyando su aseveración en diversos pronunciamientos constitucionales que aunque ya conocidos, parece adecuado recordar:

- STC 37/1981, (F.J. $5^{\circ}$ ) que reconoce que la distinción entre personal funcionario y laboral es un principio organizativo básico integrado en el título competencial del régimen jurídico de las administraciones públicas.

- STC 178/1989, (F.J. $6^{\circ}$ ) que incorpora la materia de incompatibilidades del personal al servicio de las administraciones públicas en el ámbito competencial del artículo 149.1.18 CE.

- STC 75/1990 y STC 98/1985, que reconocen la competencia estatal básica para la regulación del régimen estatutario de los funcionarios públicos dado su marcado carácter instrumental y su función de garantía para asegurar el respeto del principio de igualdad.

- STC 99/1987 (F.J. $3^{\circ}$ ), reconoce competencia estatal para la regulación de la normativa sobre la adquisición y pérdida de la condición de funcionario, las condiciones de promoción de la carrera administrativa, las situaciones administrativas, derechos y deberes, régimen disciplinario, acceso a los cuerpos y escalas funcionariales y la forma de provisión de puestos de trabajo.

2.- Otra posición al respecto, si bien, claramente continuista es la de TRAYTER I JIMENEZ $Z^{25}$, el autor destaca como la sentencia STC 76/1983, tras examinar la posibilidad de dos concepciones, siguiendo en este punto a $P A R A D A$ VAZQUEZ ${ }^{26}$, con relación al régimen estatutario y su conexión con el régimen jurídico de las administraciones, entiende que la cuestión se resuelve de conformidad con lo declarado en la ya citada sentencia que señala:

«El artículo 149.1.18 de la Constitución reconoce al Estado competencia exclusiva para dictar las bases del régimen jurídico de las Administraciones públicas y del régimen estatutario de sus funcionarios. De ello deriva una doble competencia estatal en materia de función pública: $1{ }^{a}{ }^{a}$ competencia para regular los aspectos básicos de la situación personal de los funcionarios públicos; es decir, de la denominada relación de servicio, contenido indiscutible del régimen estatutario, y $2 .^{a}$ ) competencia para regular los aspectos esenciales de la organización de la burocracia de las Administraciones

\footnotetext{
25 Véase, J.M. TraYter I J.M. JiMÉnEZ, «La Conflictivitat Competencial - Las Bases del Régim Estatutari dels Funcionaris Públics», Edit. Institut d'Estudis Autonómics, Barcelona, 1993, pp. 14 y ss.

26 Véase, R. PARAda VÁzQUEZ, «Derecho Administrativo - Organización y Empleo Público» Vol. II, Edit. Marcial Pons, Madrid, 1997, p. 241 y ss.
} 
REFLEXIONES EN TORNO AL INFORME PARA LA PREPARACIÓN DE UN ESTATUTO BÁSICO DEL EMPLEADO PÚBLICO...

públicas, pues la expresión «régimen jurídico» contenida en el precepto constitucional no se refiere exclusivamente al procedimiento y al régimen de recursos, como ha señalado este Tribunal Constitucional en su sentencia 32/1981, de 28 de julio, y ha de entenderse incluida también en ella la regulación básica de la organización de todas las Administraciones públicas».

Así pues, la opción constitucional no ofrece dudas, estamos en presencia de un ámbito de lo básico reconocido expresamente por el Tribunal Constitucional que alcanza no solo las competencias estrictamente jurídicas, sino también sobre las reglas que definen el modelo y tipo de organización de la Función Pública, de forma que el título competencial del régimen jurídico también se extiende sobre la organización de la burocracia.

3.- Continuando con nuestro estudio entendemos que es muy interesante la posición manifestada por TORNOS MAS ${ }^{27}$, y en especial dada su actual presencia en el debate autonómico, entendía este que la legislación autonómica en el ámbito material de la función pública tiene unos límites concretos en los artículos 23.2, 28.1 y 103.3 CE. , a lo que debe añadirse que la actual configuración del Estatuto de Cataluña (en este sentido homologable al resto) supone que la competencia autonómica debe ser ejercida de acuerdo con los términos en que fue asumida, y así, en concreto, la remisión expresa a la determinación de las bases estatales (149.1.18). Asimismo, destaca el autor como el Tribunal Constitucional en sus STC 76/1983 y 99/1987 declara que la competencia autonómica queda condicionada al desarrollo por el Estado de dos títulos competenciales propios (Régimen Jurídico y Régimen del Estatuto de la Función Pública), para finalizar afirmando que precisamente este reconocimiento por el Alto Tribunal ha legitimado que el legislador estatal haya podido dictar una regulación básica de contenido amplio en la que ha predeterminado tanto el modelo de función pública como la relación estatutaria de los funcionarios, no manifestando reparo alguno a esa configuración jurídico constitucional.

4.- Asimismo, entendemos también interesante la posición sostenida por MONTORO CHINER ${ }^{28}$, parte en su análisis de la situación consolidada en el año 1995, pero entiende necesario reflexionar sobre la situación que en aquel momento se generaba con motivo de la necesidad de aprobación de un Estatuto de la Función Pública, considerando que la posi-

\footnotetext{
27 Véase, J. Tornos MAs, en la obra VV.AA. «Manual de Dret Public de Catalunya», Edit. Institut d'Estudis Autonomics, Barcelona, 1992, p. 429 y ss.

28 Véase, Maj. Montoro Chiner, «Para la Reforma del Empleo Público: Nueve Proposiciones», Revista de Administración Pública, n. ${ }^{\circ} 136$, pp. 197 y ss.
} 
ción del legislador estatal era ya en aquellos momentos complicada. Así, llama la atención sobre la posibilidad de que las Comunidades Autónomas tengan que modificar su legislación con motivo de una nueva legislación básica, pero posteriormente incorpora una cuestión que es el centro de nuestro trabajo, en concreto, analiza la posibilidad de una nueva regulación que aligere lo básico de forma que las comunidades autónomas gozarían de un mayor margen de capacidad material de regulación legislativa, ahora bien, el autor nada nos dice sobre lo acertado desde el punto de vista constitucional de una decisión del legislador de renunciar expresamente a reducir el ámbito de lo básico que el propio Tribunal Constitucional ha reconocido como conforme al vigente marco de reparto competencial.

Sostiene igualmente que a su entender las bases es una cuestión más de intensidad que no de extensión, si bien, considera igualmente que hay aspectos básicos del estatuto que por afectar a derechos fundamentales (sistema de acceso, negociación colectiva, régimen disciplinario) deben ser objeto de una regulación más intensa por parte del legislador estatal, mientras que los otros ámbitos materiales es exigible un acuerdo Estado con las CCAA para reducir el límite de lo básico.

5.- Por último, consideramos de gran interés lo expuesto por SÁNCHEZ MORÓN ${ }^{29}$, así, en su trabajo ya presenta unas importantes propuestas y reflexiones sobre la posibilidad de elaboración de un Estatuto que comprendiera la regulación de los contenidos comunes al conjunto del empleo público, reseñando un listado de materias de necesaria incorporación al mismo, habiéndose observado que las mismas han sido objeto de incorporación a las propuestas de la Comisión, ahora bien, lo que más nos interesa en este momento son las propuestas que incorpora con relación a los concretos aspectos que entiende deben ser objeto de regulación por la legislación básica del Estado y el alcance de esta normativa.

De todas formas con carácter previo debemos señalar la preocupación del autor por la decisión del Tribunal Constitucional en su STC 99/1987, ya que a su entender hay que distinguir entre aspecto subjetivo de la función pública, es decir, los aspectos básicos de la situación personal de los funcionaros o relación de servicio y el aspecto objetivo u organizativo, y esta distinción no es reconocida por el Alto Tribunal, ya que este incluye

\footnotetext{
29 Véase, M. SÁnchez Morón, en la obra VV.AA., «Situación actual y tendencias de la función pública española», el artículo «Nuevo marco jurídico y competencial del personal al servicio de las administraciones», Edit. Comares, Granada 1998, pp. 71 y ss.
} 
en el contenido del Estatuto contenidos de naturaleza organizativa. Ahora bien, eso no supone que el autor rechace que la «legislación especifica sobre la función pública no pueda extenderse a aspectos objetivos de la organización del empleo público» ${ }^{30}$, sino que entiende que estos aspectos no forman parte strictu sensu del Estatuto de los funcionarios, ni su fundamento se encuentra en el título competencial de las «Bases del régimen estatutario de los funcionarios», sino que el título se encuentra en las «Bases del régimen jurídico de las Administraciones Públicas», coincidiendo en la delimitación del título competencial con otros sectores doctrinales, debiendo indicar por nuestra parte también nuestra conformidad con esta última consideración.

Ahora bien, a la luz de estas consideraciones el autor reclama que un futuro estatuto debería tener en cuenta la necesidad de flexibilizar las normas organizativas para conseguir un funcionamiento más eficaz de las administraciones, asimismo estos aspectos solamente deben incorporarse al futuro Estatuto (subjetivo) de la función pública en lo estrictamente indispensable «para regular las bases de la carrera administrativa (en la medida que exista) y la promoción profesional» ${ }^{31}$.

En cuanto al ámbito material de una futura legislación del Estado, reclama expresamente las siguientes áreas:

- Los Principios y sistemas de acceso al empleo público.

- La pérdida de la condición de empleado público.

- Reglas sobre la carrera, promoción y en su caso provisión de puestos de trabajo.

- Peculiaridades de la representación y participación de los empleados.

- Negociación colectiva y Derecho de negociación.

- Incompatibilidades, Régimen disciplinario y Responsabilidad de los empleados públicos.

- Sistema retributivo, situaciones administrativas, derechos laborales, normas sobre movilidad.

Por último reclama la exclusión, en virtud de las competencias autonómicas de autoorganización la determinación de los cuerpos y escalas de las administraciones autonómicas.

En cuanto a la extensión entiende el autor que con pleno respeto a las previsiones constitucionales de los artículos 149.1.1 y 23.2 CE, la legisla-

\footnotetext{
30 Ibid., p. 69.

31 Ibid., p. 70.
} 
ción básica debe respetar la autonomía organizativa y financiera de las Comunidades Autónomas, lo que exige su entender, una regulación flexible, descentralizada y diferenciada que respete los ámbitos competenciales autonómicos, de forma que el legislador estatal debe ser menos rígido, en especial en los contenidos de carácter organizativo.

\section{B) Examen de últimas posiciones doctrinales:}

A la vista de todo lo anteriormente expuesto, entendemos de todo punto preciso para una adecuada y completa visión de la cuestión incorporar aquellos estudios que recopilen los últimos pronunciamientos del Tribunal Constitucional sobre la materia de función pública y asimismo, también las posiciones que sobre esta concreta cuestión formulan los sectores doctrinales que encabezan las nuevas propuestas de reforma y relectura del reparto competencial.

1.- Iniciamos nuestro examen por la posición sostenida por Parejo Alfon$\mathrm{so}^{32}$, con relación a los títulos competenciales que entran en juego en el área material de la Función Pública, en primer lugar, tenemos el título proveniente de lo dispuesto por el artículo 149.1.18 CE que atribuye la competencia al legislador estatal de regular el régimen básico de la función pública, contenido expresamente reconocido por varias sentencias del Tribunal Constitucional (SsTC 99/1987 y 37/2002 entre otras), planteamiento este que coincide con las posiciones doctrinales anteriormente expuestas.

Ahora bien, cuál es el contenido y objeto de este régimen jurídico del poder público reconocido por el artículo 149.1.18 CE, y a este respecto nos remitimos a las consideraciones del citado autor ${ }^{33}$, que señala como estas bases tienen una doble función, la primera acotar la extensión de la competencia estatal que se encontrara referida a los contenidos materiales que supongan «un común denominador normativo de la misma», de forma que esta regulación se constituye en un límite de la potestad de autoorganización de las Comunidades Autónomas ${ }^{34}$ y la segunda, es que esta com-

\footnotetext{
32 Véase, L. Parejo Alfonso, en la obra VV.AA. «El Estatuto de la Función Pública a debate», el artículo «Límites del desarrollo del Estatuto por las Comunidades Autónomas», Edit. UNED- Colex, Madrid, 2003, pp. 33 y ss.

33 Véase, L. PARejo Alfonso, en la obra VV.AA. «Administraciones Públicas y Constitución», el artículo «El ciudadano y el administrado ante la Administración y su actuación», Edit. INAP, Madrid, 1998, pp. 542 y ss.

34 Véase, R. Gómez-Ferrer Morant, «Relaciones entre leyes: jerarquía, competencia y función constitucional, $R A P$ n. ${ }^{\circ} 113,1987$, p. 54, el cual introduce el concepto de «función constitucional»,
} 
petencia estatal tiene su objeto en el régimen organizativo y de funcionamiento del poder público administrativo en su conjunto y por lo tanto, también el de las Comunidades Autónomas (SsTC 32/1981, 76/1983, 14/1986 y 27/1987), avanzando ya en ese momento su necesaria reconducción al principio de unidad constitucional material y conexión con la exigencia constitucional de un único orden de derechos y libertades como de valores y principios rectores de las políticas públicas, cuestión esta que como veremos posteriormente tiene una directa proyección sobre el ámbito de los contenidos materiales afectados por el Estatuto de la Función Pública.

A la vista de lo anterior procede continuar con el estudio de la complejidad de títulos concurrentes dada su especial trascendencia en los momentos actuales del debate, anticipando al respecto que por nuestra parte compartimos los argumentos que a continuación se van a exponer y que entendemos pueden ser parte importante del soporte a nuestra tesis central en este trabajo. Así, señala PAREJO ALFONSO ${ }^{35}$ que no debe olvidarse que el Tribunal Constitucional también ha reconocido a las Comunidades Autónomas un ámbito competencial propio como ya veíamos anteriormente, cuyo fundamento se encuentra en sus propios Estatutos de Autonomía los cuales a su vez se encuentran integrados en el denominado «bloque de constitucionalidad», que permite a las Comunidades Autónomas el que puedan desarrollar su ejercicio competencial pero supeditado al limite del común denominador normativo antes señalado, dado que estamos en presencia de un ámbito material que afecta a una cuestión tan esencial como es la potestad de autoorganización de las Comunidades Autónomas, actuando asimismo de forma conjunta con el artículo 149.1.18 CE. y como última frontera las previsiones del artículo 149.1.1. CE.

Examinemos ahora las consecuencias sobre los títulos competenciales del último pronunciamiento del Tribunal Constitucional, en concreto, la STC 37/2002 (Fund. Jco. 12 ), donde este manifiesta la pertinencia de que se reclame la aplicación del título recogido en el artículo 149.1.1.CE. al ámbito material de la Función Pública, dado que existen contenidos de los incluidos en la enumeración del artículo 103.3 CE y así reconocidos por la STC 99/1987 susceptibles de ser afectados de forma directa por ese

\footnotetext{
de manera que esta noción parte de la consideración de que las normas básicas permiten salvaguardar unos mínimos uniformes en todo el territorio nacional en aras de un interés general que define la propia norma básica.

35 Véase, L. Parejo Alfonso, en la obra op. cit. VV.AA. «El Estatuto de la Función Pública a .......», pp. 34 y ss.
} 
título específicamente estatal para establecer las condiciones básicas que garanticen la igualdad de todos los españoles en el ejercicio de los derechos y el cumplimiento de sus deberes constitucionales. Ahora bien, cómo puede actuar este título, la respuesta nos la da el propio Tribunal Constitucional al considerar que este no habilita al Estado para regular la materia misma en la que aparezcan los derechos y deberes, sino para establecer un marco normativo que fije las «condiciones de ejercicio» de estos derechos, de forma que estas previsiones normativas se constituyan en un límite negativo del ámbito competencial legislativo de las Comunidades Autónomas.

De todo lo expuesto hasta este momento se puede concluir, como destaca el citado autor, que el régimen jurídico en el ámbito de la función pública se encuentra configurado en primer lugar, por la legislación básica estatal dictada al amparo de las previsiones del artículo 149.1.18 CE., y desarrollada por las respectivas legislaciones autonómicas específicas y en segundo lugar, pero con incidencia paralela al otro título, las condiciones básicas dictadas de conformidad con las previsiones del artículo 149.1.1.CE de forma que indica en sentido negativo los límites de la legislación autonómica. Ahora bien, el problema a resolver a continuación es la articulación jurídica entre ambos títulos competenciales, ya que por un lado, el Tribunal Constitucional no presenta modulación o variación sobre su criterio de entender que el legislador estatal goza de un amplio margen para desarrollar su competencia legislativa sobre lo básico al amparo de las precisiones del artículo 149.1.18 CE y por otro debe tenerse en cuenta que las previsiones del artículo 149.1.1 CE no significan una prohibición de regulación divergente a la legislación estatal por parte de las comunidades Autónomas sino «el respeto de las condiciones de ejercicio en igualdad, lo que supone que estemos en presencia de un mínimo común denominador básico y también ante un mínimo común garantizador de la igualdad en las posiciones básicas ${ }^{36}$ al amparo del 149.1.1 CE y a este respecto el autor nos ofrece una solución, a nuestro entender satisfactoria, al considerar que el Tribunal Constitucional en este punto ha vuelto a sostener que las previsiones del artículo 149.1.1 CE deben ser entendidas como complementarias del título material de la función pública (149.1.18 $\mathrm{CE}$ ). Así, como continúa afirmando, cuándo el legislador estatal entendiera como necesario el legislar sobre materias, en principio no básicas, para dar cumplida cuenta de su competencia para regular adecuadamente el «mínimo común uniforme» del Estatuto Básico de la Función Pública,

36 Véase, L. PARejo Alfonso, en la obra op. cit. VV.AA. «El Estatuto de la Función Pública a
.......», pp. 38. 
podría entonces reclamar la aplicación del título derivado de las previsiones del artículo 149.1.1 CE, con lo que se resuelve el ámbito de actuación de cada título competencial, además, de confirmar la amplia competencia estatal para la regulación de un Estatuto básico de la función pública, cuestión esta reconocida por el Tribunal Constitucional.

En cuánto a la densidad de la regulación de las bases constituye otro de los puntos examinados por el citado autor manifestando a este respecto tras un repaso a la doctrina general del Tribunal Constitucional sobre las bases y que obviamos por ya expuesta al comienzo de este trabajo, afirmando como resumen que el título competencial general del artículo 149.1.18 CE se configura como un mínimo común indisponible por las Comunidades Autónomas y las previsiones del artículo 149.1.1. se constituirían por lo tanto como un complemento necesario, dado que ante la posibilidad de que el desarrollo legislativo autonómico respetara el ámbito material básico no obstante la regulación autonómica podría entrar en contradicción con la igualdad básica con relación al ejercicio de los derechos y deberes constitucionales de los funcionarios, los cuales deben estar garantizados en cualquier organización administrativa. Afirmando posteriormente la existencia de una amplia libertad reconocida constitucionalmente al legislador básico estatal para la regulación más o menos extensiva y cualitativa del Estatuto de la Función Pública en función de las exigencias de los intereses generales y el respeto al espacio competencial autonómico, con lo cual las Comunidades Autónomas dependerán siempre de una previa decisión del legislador estatal, ahora bien, referida esta al mínimo común uniforme y las garantías del 149.1.1. CE.

2.- Por último, queremos examinar la posición sostenida en el «Informe sobre la Reforma del Estatuto» ${ }^{37}$, así, este reconoce la existencia de una reserva competencial clara a favor del Estado al amparo de las previsiones del artículo 149.1.18 CE y también una asunción limitada de competencias por el juego del artículo 10 de su estatuto que se remite a los límites derivados de las propias bases estatales, lo cual lleva a concluir a los autores que existe en estos momentos un mínimo ámbito competencial de la comunidad autónoma, planteando como alternativas a la actual situación, en primer lugar, la modificación del texto constitucional mediante la reforma del artículo $149 \mathrm{CE}$, o bien proceder a la calificación de las competencias del artículo 10 de su Estatuto como exclusivas.

Posteriormente, examinan con carácter más detallado las competencias en el ámbito de la Función Pública reconociendo que la interpretación del

37 Véase, op. cit. «Estudio sobre ....», pp. 106 y ss. (versión en castellano). 
actual marco constitucional se ha consolidado en un sentido claramente expansivo de forma que la competencia estatal alcanza a todos los aspectos propios de la regulación del estatuto funcionarial incluidos los relacionados con el ámbito organizativo, cuestión esta que ya hemos podido apreciar en anteriores apartados de este trabajo; concluyendo su examen con la formulación de una propuesta fundamentada en la existencia de unos derechos históricos de Cataluña que permitiría reclamar un trato igual al de la Comunidad Foral de Navarra reconocido por la STC 140/1990.

\section{C) Conclusiones finales:}

Tras examinar en los apartados anteriores la situación del debate entendemos alcanzado el momento en que debemos expresar nuestras consideraciones al respecto y por lo tanto formular una serie de conclusiones que nos van a servir de soporte esencial para un adecuado examen y contraste de posiciones con las tesis manifestadas en el Informe sobre el futuro Estatuto del Empleado Público.

1.- Así, deberíamos contestar a una primera cuestión, y esta no sería otra que fijar cuales son los títulos competenciales que amparan al Estado para proceder a una regulación de lo básico y la amplitud de esa facultad sobre el ámbito material de la función pública, de manera que a la vista de todo lo expuesto entendemos que es mayoritaria la consideración tanto doctrinal ${ }^{38}$ como de nuestro Tribunal Constitucional ${ }^{39}$, de considerar que la competencia autonómica queda condicionada de entrada al desarrollo por el Estado de los títulos competenciales reconocidos por las previsiones del artículo 149.1.18, es decir, competencia estatal para regular los aspectos esenciales de la organización burocrática de forma que alcanzaría el establecimiento del modelo y tipo de organización de la función pública amparado todo ello por el título competencial del Régimen jurídico y, por otro lado, la competencia para la elaboración del régimen estatutario del personal al servicio de las Administraciones Públicas.

\footnotetext{
38 Véase, Figuera I M. Lluch, op. cit. «La Conflictivitat Competencial - El Régim Jurídic.......ppp. 33 y ss., también TrAYTER I J.M. JiMÉNEZ, «La Conflictivitat Competencial - Las Bases del Régim Estatutari dels ....» pp. 14 y ss. e igualmente J. TORNos MAS, en la obra VV.AA. «Manual de Dret Public de ...», p. 429 y ss. y por último L. PARejo Alfonso, en la obra op. cit. VV.AA. «El Estatuto de la Función Pública a .......», pp. 33 y ss.

39 En concreto, nos remitimos a las más destacadas al respecto SsTC 37/1981, 76/1983, 99/1987 y $37 / 2002$.
} 
Ahora bien, tal como ya indicamos anteriormente esta precisión inicial necesita ser complementada y en este punto ya manifestamos nuestra coincidencia con las posiciones de PAREJO ALFONSO ${ }^{40}$, en ese sentido hay que tener en cuenta que el Tribunal Constitucional ha reconocido a las Comunidades Autónomas un ámbito competencial propio al amparo de las previsiones reconocidas por sus propios Estatutos de Autonomía, los cuales a su vez se encuentran integrados en el denominado «bloque de constitucionalidad», lo que permite a las Comunidades Autónomas el desarrollo de sus competencias en esta materia y más aún si tenemos en consideración que estamos en presencia de un ámbito material que afecta a una cuestión tan esencial como es su potestad de autoorganización, pero todo ello supeditado siempre al limite del común denominador normativo como señala el citado autor. Así pues, admitido que el título competencial general del artículo 149.1.18 CE y el sentido de su configuración, debemos responder a la cuestión de sí este es el único título aplicable en esta área material ó procede complementar el mismo con las previsiones de algún otro, y la respuesta nos la da el propio Tribunal Constitucional en su STC 37/2002, (F.J. 12) al considerar las previsiones del artículo 149.1.1. CE como un complemento necesario, dado que la regulación autonómica nunca podrá entrar en contradicción con la igualdad básica con relación al ejercicio de los derechos y deberes constitucionales de los funcionarios, los cuales deben estar garantizados en cualquier organización administrativa.

Como conclusión de lo expuesto a nuestro entender no existe duda alguna, como reconocen también los autores del «Informe sobre la reforma del estatuto» ${ }^{41}$, de la existencia de una amplia libertad reconocida constitucionalmente al legislador básico estatal para la regulación extensiva y cualitativa del Estatuto de la Función Pública, amparada la misma en las previsiones de los artículos 149.1.18 y 149.1.1 CE, en cuánto títulos competenciales, pues el que estemos en presencia de un mínimo común, no significa que se le reste un ápice de capacidad al legislador básico, y todo ello, sin olvidar también la incidencia tanto jurídico material como axiológica del artículo 103 C.E. como comprobaremos posteriormente.

\footnotetext{
40 Véase, L. Parejo Alfonso, en la obra op. cit. VV.AA. «El Estatuto de la Función Pública a .......», pp. 33 y ss.

${ }^{41}$ Véase, op. cit. «Estudio sobre...», p. 106 y ss., señalando los autores que no existe duda alguna de que en el actual marco constitucional se ha consolidado una competencia estatal que alcanza todos los aspectos propios de la regulación del Estatuto funcionarial incluidos los relacionados con el ámbito organizativo, lo que supone la existencia de una amplia libertad competencial del legislador básico para regular esta materia.
} 
Asimismo, estas conclusiones se formulan también a la vista del actual marco normativo constitucional ya que la propuesta de elaboración del Estatuto de los empleados públicos no puede ser analizada ni formulada en previsión de «supuestas o futuras» reformas estatutarias que por otra parte, entendemos que las mismas aunque introdujeran nuevas calificaciones competenciales (exclusividad), no por ello, se podría hablar de una reducción de las competencias estatales, dado que recordemos siempre hemos hablado de «mínimo común» y este núcleo esencial es indisponible a nuestro entender, salvo reforma constitucional que no simplemente estatutaria, o bien, la introducción de conceptos como los «Derechos Históricos», tal como propone el «Estudio para la reforma del estatuto» ${ }^{42}$, si bien, estimo que el estudio y valoración de esta cuestión excede el sentido y finalidad del presente trabajo.

\section{CONSIDERACIONES SOBRE EL CONTENIDO MATERIAL DEL ESTATUTO DE LA FUNCIÓN PÚBLICA}

El siguiente paso es determinar cuál es el contenido de lo básico reconocido por nuestro Tribunal Constitucional al legislador estatal, que si bien, como de forma reiterada ha declarado el mismo, con carácter general, este no es determinable en «abstracto y a priori» ${ }^{43}$, lo que sí podemos reseñar son una serie de materias admitidas expresamente:

1.- La fijación de la distinción entre el personal funcionario y laboral, reconocido por STC 37/1981, en su fundm. jco $5^{\circ}$.

«.....tanto más si se tiene en cuenta que, como señala la representación del Gobierno vasco, la remisión que el artículo 18 k) hace a las disposiciones vigentes no puede entenderse sino como remisión a las disposiciones pertinentes de la Ley de Entidades Estatales Autónomas y al Estatuto de Personal de los Organismos Autónomos, cuya distinción entre personal funcionario y obrero es un principio organizativo básico en el régimen jurídico de nuestras Administraciones Públicas».

2.- La normación del contenido de la relación jurídica de servicio de los funcionarios, reconocido fundamentalmente por las SsTC 99/1987 y en concreto señala la STC 37/2002 en su fundm. jurd. $8^{\circ}$ :

\footnotetext{
42 Véase, op. cit. «Estudio sobre ....», p. 112. (versión en castellano).

43 En este sentido se manifiesta la STC 99/1987, en el fundamento jurídico 3 c) que señala: «Es éste, desde luego, un ámbito cuyos contornos no pueden definirse en abstracto y a priori, pero en el que ha de entenderse comprendida, en principio, la normación.....»
} 
REFLEXIONES EN TORNO AL INFORME PARA LA PREPARACIÓN DE UN ESTATUTO BÁSICO DEL EMPLEADO PÚBLICO...

Por otra parte, en relación con el contenido de la expresión «régimen estatutario de los funcionarios públicos», empleada por los arts. 103.3 y 149.1.18 ${ }^{a}$ CE, el Tribunal Constitucional ha tenido ocasión de declarar, poniendo en conexión ambos preceptos constitucionales, «que sus contornos no pueden definirse en abstracto y «a priori»», debiendo entenderse comprendida en su ámbito, «en principio, la normación relativa a la adquisición y pérdida de la condición de funcionario, a las condiciones de promoción de la carrera administrativa y a las situaciones que en ésta puedan darse, a los derechos y deberes y responsabilidad de los funcionarios y a su régimen disciplinario, así como a la creación e integración, en su caso, de cuerpos y escalas funcionariales y al modo de provisión de puestos de trabajo al servicio de las Administraciones públicas» [SSTC 99/1987, de 11 de junio, F. 3 c); 56/1990, de 29 de marzo, F. 19].

3.- La regulación del régimen de incompatibilidades del personal al servicio de las administraciones públicas, el cual entendemos debe incorporarse necesariamente al ámbito del futuro Estatuto por la aplicación conjunta de las previsiones de los artículos 149.1 .18 y 103.1 y $3 \mathrm{CE}$, reconocido por la STC 178/1989, en su fundm. Jdco $6^{\circ}$ :

«En efecto, no cabe duda, que la configuración de un régimen de incompatibilidades de los empleados públicos, aplicable con criterios de generalidad a todo el sector público y con el detalle necesario que garantice una igualdad de tratamiento de los mismos, a esos efectos, en todo el territorio nacional, con independencia de la Administración o ente público al que sirvan, forma parte del régimen jurídico de las Administraciones Públicas, al que se refiere, para reservar al Estado la regulación de las bases del mismo, el art. 149.1.18 de la Constitución.

Así, aunque el sistema de incompatibilidades aplicable a los funcionarios públicos pudiera incluirse en el régimen estatutario de los mismos y, en consecuencia, el título competencial del Estado en este caso sería el relativo a las bases del mencionado régimen estatutario (como así hace explícitamente la Disposición final primera de la Ley 53/1984), dada la amplitud con que la Ley ha diseñado dicho sistema, que contempla, además, tanto el sistema de incompatibilidades de los empleados públicos no sometidos a una relación funcionarial como, en términos más generales y comprensivos, el sistema de incompatibilidades del personal, cualquiera que sea el régimen jurídico al que esté sujeto, que se halle al servicio del sector público, debe encuadrarse dentro del régimen jurídico de las Administraciones Públicas, siendo, por tanto, competencia del Estado, en todo caso, el establecimiento de las bases relativas al mismo.

4.- También formaría parte del contenido de un futuro Estatuto la regulación normativa de las retribuciones de los funcionarios, como declara la SsTC 63/1986, 99/1987, 103/1997, 385/1993 y por todas la STC 96/1990, en su fundam. jurd. $3^{\circ}$ :

«La cuestión planteada ya ha sido resuelta por el Tribunal Constitucional en su STC 63/1986, a cuya doctrina no cabe ahora sino remitirse. En efecto, como se decía en la Sentencia aludida (fundamento jurídico 11) la competencia estatal invocada, en primer lugar (ex art. 149.1.18 C. E.), para regular las bases del régimen estatutario de los funcionarios, puede extenderse a incluir en ella "previsiones relativas a las retribuciones de los funcionarios, comunes a todas las Administraciones Públicas, lo 
que, a su vez, hallaría fundamento en los principios constitucionales de igualdad y solidaridad».

5.- Por último, también podemos entender que formaría parte del futuro estatuto los derechos sindicales y de negociación de los funcionarios, si bien, en este punto solamente existe una única y muy temprana sentencia del Tribunal Constitucional (STC 57/1982) que analice específicamente este tema y sus conclusiones no son precisamente favorables al reconocimiento de estos derechos, a pesar de ello, entendemos en este punto que de la posterior jurisprudencia general de ese Tribunal se pueden formular unas conclusiones diferentes como ya hemos señalado en otro trabajo ${ }^{44}$, en el sentido de reconocer como parte integrante de los derechos de los funcionarios los de esta naturaleza, y por ello, formar parte también necesaria del futuro estatuto.

De lo anteriormente expuesto se puede concluir que el ámbito material del contenido de un futuro estatuto de la función pública se encuentra perfectamente delimitado y, no de forma abstracta y a priori, sino como consecuencia del examen detallado y exhaustivo del Tribunal Constitucional en concretos supuestos sobre la vigente legislación post-constitucional dictada con el carácter de «bases» por el legislador estatal, de forma que podemos extraer tres conclusiones esenciales sobre la trascendencia jurídico constitucional de esa legislación, así ese Alto Tribunal declaro:

a) Que las normas post constitucionales que regulen estos ámbitos materiales tendrán el carácter de ordenadoras del Estatuto de la Función Pública, y así lo expresa en la STC 99/1987 fund. Jco. 3 c):

«Las normas que disciplinen estos ámbitos serán, en el concepto constitucional, ordenadoras del Estatuto de los funcionarios públicos, pues todas ellas interesarán directamente a las relaciones entre éstos y las Administraciones a las que sirven, configurando así el régimen jurídico en el que pueda nacer y desenvolverse la condición de funcionario y ordenando su posición propia en el seno de la Administración».

b) Que este conjunto de normas dictadas por el legislador básico ha supuesto una regulación completa de la materia que forma parte del Estatuto de la Función Pública, precisando además el Tribunal Constitucional las normas que deben ser tomadas en consideración a estos efectos, a través de la STC 37/2002, fund. jco. 9:

«El legislador estatal postconstitucional ha procedido a regular de manera completa, al menos, aparentemente, las bases del régimen estatutario de los funcionarios públicos. Dichas bases, aplicables, en lo que ahora interesa, a los funcionarios de todas las Admi-

${ }^{44}$ Véase, J. Fondevila Antolin, op. cit. «Constitución y Empleo Público....», pp. 185 y ss. 
REFLEXIONES EN TORNO AL INFORME PARA LA PREPARACIÓN DE UN ESTATUTO BÁSICO DEL EMPLEADO PÚBLICO...

nistraciones públicas, sin perjuicio, por tanto, de las previsiones específicas, resulten o no básicas, relativas a concretos regímenes funcionariales, están contenidas, principalmente, en la Ley 30/1984, de 2 de agosto, de medidas para la reforma de la función pública, en la Ley 53/1984, de 26 de diciembre, de incompatibilidades del personal al servicio de las Administraciones públicas y en la Lev 9/1987. de 12 de junio, de órganos de representación, determinación de las condiciones de trabajo y participación del personal al servicio de las Administraciones públicas, así como en las disposiciones legales que las modificaron».

c) Asimismo, ese Alto Tribunal niega el carácter básico de la Ley de Funcionarios Civiles del Estado de 1964 por inferencia natural, lo que no significa que el Estado no sea titular de la competencia de algunos aspectos regulados por la misma, ni tampoco que dichos aspectos no puedan aplicarse por la vía del derecho supletorio, así lo declara en la ya citada STC 37/2002, fund. jco 9:

«Así pues, habiendo procedido el legislador postconstitucional a establecer de manera aparentemente completa e innovadora las bases del régimen estatutario de los funcionarios de las Administraciones públicas, definiendo en cuanto al régimen disciplinario como norma básica común a todos ellos el art. 31 de la Ley 30/1984, de 2 de agosto, no cabe atribuir, de conformidad con la doctrina antes expuesta, naturaleza básica a los preceptos de la Ley de funcionarios civiles del Estado de 1964 referidos al mencionado régimen disciplinario, al no haber sido declarados expresamente como básicos por el legislador estatal postconstitucional, ni poder inferirse dicho carácter de su posible consideración como complemento necesario de las normas básicas postconstitucionales, al no existir dato alguno que permita deducir de manera cierta y clara que el legislador postconstitucional no haya pretendido agotar la regulación de los aspectos que ha estimado básicos de la materia».

De los pronunciamientos examinados podemos observar importantes puntos de referencia sobre la situación en la que nos encontramos actualmente, de forma que no existe duda de que estamos en presencia de una regulación no homogénea desde un punto de vista formal ( Estatuto de la Función Pública), pero sí completa e innovadora desde un punto de vista material, es decir, estamos en presencia de unas completas normas reguladoras de las bases del régimen estatutario de los funcionarios públicos, si bien, el máximo intérprete constitucional también considera que ese carácter completo y por lo tanto de agotamiento del ámbito competencial es solo aparente, reconociendo con ello, dos cuestiones, en primer lugar, el hecho de que el actual contenido material de las bases aprobadas por el legislador post-constitucional no exceden en ningún caso del reparto competencial reconocido al mismo, y en segundo lugar, que la actual regulación podría ser todavía susceptible de modificación pero en sentido ampliatorio, si bien, en coherencia con la propia doctrina constitucional ya examinada, esas consideraciones no pueden formularse en abstracto y por ello, necesitarían de una posterior regulación estatal para contrastar esa posibilidad de ampliación. A todo 
lo anterior debemos añadir otra cuestión, en concreto, que estas conclusiones son formuladas por el Tribunal Constitucional tras el examen de unas concretas normas a las que otorga materialmente naturaleza estatutaria y por ende, esto significa que la declaración de reparto competencial conforme con la Constitución no se ha realizado en abstracto sino tras el examen concreto del conjunto de ese ordenamiento sectorial.

\section{ESTATUTO DE MÍNIMOS O RENUNCIA A LA COMPETENCIA SOBRE LO BÁSICO CONSTITUCIONALMENTE RECONOCIDA}

Efectivamente nos encontramos ante una cuestión esencial para el futuro desarrollo de un estatuto de la función pública o como lo califica el Informe de la Comisión de Expertos el «Estatuto Básico del Empleado Público», y esta no es otra que el alcance del contenido básico del mismo. El citado informe opta claramente tanto en sus primeras consideraciones, como en el desarrollo de los diferentes ámbitos materiales, en especial el referido a la carrera administrativa, por lo que denomina un "estatuto de mínimos» ${ }^{45}$ argumentando en su defensa diversas consideraciones que podemos dividir en dos apartados, a saber: el primero de carácter meramente jurídico y un segundo donde la argumentación gira en torno a consideraciones de lo que podríamos llamar política de organización de personal.

Dado que el objeto de este trabajo es puramente el análisis jurídico de algunos de los contenidos del Informe, no entraremos al examen de los argumentos referidos al segundo apartado, sí bien, no podemos evitar formular unas breves consideraciones, en primer lugar, se afirma en el documento que la actual legislación es excesivamente uniforme lo que ha provocado la aparición de regímenes o estatutos especiales ${ }^{46}$, pero esta argumentación no puede servir de soporte para proponer una reducción de las normas básicas, por cuanto, con relación a la existencia de estatutos especiales, recordemos que ya la propia normativa básica Ley 30/1984 de Medidas para la Reforma de la Función Pública en su artículo $1^{\circ} .2$ preveía el establecimiento de normas específicas para un determinado grupo de $\operatorname{colectivos}^{47}$, por lo tanto el mecanismo organizativo y legal existe actual-

\footnotetext{
45 Véase, op. cit. Informe de la Comisión «Estatuto Básico.....», p. 35.

46 Véase, op. cit. Informe de la Comisión «Estatuto Básico.....», p. 25.

47 Así, la Ley 30/1984, establece en concreto: «En aplicación de esta Ley podrán dictarse normas específicas para adecuarla a las peculiaridades del personal docente e investigador, sanitario, de los servicios postales y de telecomunicación y del personal destinado en el extranjero».
} 
mente, destacando que en este momento ya se ha hecho amplio uso de las previsiones establecidas en el mismo con lo cual carece de sentido las objeciones del informe; pero es más reconoce el propio documento que en otros casos estamos en presencia de un intento de «huida de las rigideces de la legislación básica» o lo que realmente es a nuestro entender y de algún miembro de la Comisión ${ }^{48}$ una «huida del derecho administrativo», cuestión que ya tuvimos ocasión de criticar en otro trabajo ${ }^{49}$ pudiendo destacar a este respecto la existencia de un reclutamiento indiscriminado y generalizado de personal bajo una relación jurídico laboral efectuada en los «Entes Públicos» y en otros casos por las denominadas «Autoridades Independientes», sorprendiendo las distorsiones que aparecen en el ejercicio de las funciones de «autoridad o soberanía» ${ }^{50}$. Así, podemos citar como ejemplos más significativos la «Comisión Nacional del Mercado de Valores», regulada por la Ley 24/1988, de 28 de julio, que en primer lugar establece que el personal a su servicio será exclusivamente de carácter laboral, para continuar en su artículo 97 y 98 atribuyendo competencias a la citada comisión de naturaleza Inspectora y sancionadora, si aplicáramos los criterios seguidos por la Doctrina más amplia deberíamos concluir que nos encontramos ante funciones de las denominadas de "autoridad o soberanía», y como consecuencia de ello, el personal a su servicio debería ser funcionario sin que existan razones para que su régimen jurídico sea diferente a los pertenecientes a otras organizaciones.

Otro ejemplo característico lo encontramos en la «Agencia de Protección de Datos», creada por la Ley Orgánica 5/1992, de 20 de Octubre, que en su artículo 34.4 establece que el personal a su servicio estará compuesto por funcionarios, pero también admite «personal contratado» según las funciones, con lo que nos encontramos con una cláusula abierta que permite vaciar de contenido las primeras previsiones del artículo, pues no existen limites que permitan fijar en que casos debe acudirse a uno u otro tipo de relación lo cual es muy grave a nuestro entender, y más si tenemos en cuenta que el artículo 36 de la misma norma, atribuye funciones a la Agencia en cuanto al ejercicio de Potestad sancionadora y también Autorizaciones y por ello,

\footnotetext{
48 Véase, M. SÁnchez Morón, «Derecho de la Función Pública», Edit. Tecnos, Madrid 1997, p. 50.

49 J. Fondevila Antolin, op. cit. «Constitución y Empleo Público...», pp. 155 y ss.

50 Véase, R. De Vicente Domingo, op. cit., El Puesto de Trabajo en el Derecho ...., pp.75 y ss. y del mismo autor, «Los Entes instrumentales en las Leyes de Procedimiento y de Contratos de las Administraciones Públicas», Madrid, ,pp. 97-111, y por último J.M. BAÑo LEÓN , Garantía Constitucional de la Función Pública y Reforma Administrativa, en «Delitos de los funcionarios públicos (Dir. Enrique Orts Berenguer)», Consejo General del Poder Judicial, Cuadernos de Derecho Judicial, Madrid,1994, pp. 12 y ss.
} 
sorprende más la ausencia de un auténtico criterio de delimitación, pues nos encontramos solamente con una remisión en blanco.

Lo anteriormente expuesto se reproduce de forma semejante en el resto de entidades, «Ente Público Aeropuertos Españoles y Navegación Aérea "(A.E.N.A.) y «Ente público Puertos del Estado», así pues solo nos queda que expresar nuevamente nuestro rechazó a este proceso de «huida del Derecho Público» y en especial el intento de vaciar de contenido el propio mandato constitucional, y en especial el desafío al propio Tribunal Constitucional, por cuanto se están utilizando puertas traseras para no respetar la exigencia de que las relaciones de empleo público deban ser de naturaleza funcionarial con carácter general, y vemos que hoy en la práctica, a través de estos artificios institucionales, cuantitativamente y cualitativamente se acude a la contratación laboral, con la gravedad que ello supone por la ausencia de toda garantía en su funcionamiento, dado que los medios personales adscritos no son los adecuados para un funcionamiento eficaz de la administración servicial para la satisfacción del interés general y como conclusión, confirma a nuestro entender que la constatación de esta realidad no puede constituirse en el argumento suficiente $\mathrm{y}$ adecuado para justificar una reducción del contenido del estatuto a «mínimos», pues estaríamos legitimando una actuación que como se puede observar para nada respeta los propios principios constitucionales que forman parte del Estatuto único de las Administraciones Públicas de conformidad con las previsiones del artículo 103.1 CE.

Todo lo dicho anteriormente es aplicable en su integridad al segundo de los argumentos utilizados en concreto la justificación en la excesiva rigidez del actual régimen jurídico de la función pública del proceso de laboralización del empleo público, pues realmente esta práctica como ya hemos señalado igualmente en otro trabajo ha sido fruto más bien de finalidades espurias que no de una lucha por una mejora organizativa ${ }^{51}$, como confirma los actuales procesos de consolidación de empleo y en especial de funcionarización del personal laboral realizados tanto por la Administración General del Estado como por la mayoría de las Comunidades Autónomas, en un intento de consolidar situaciones «especiales» y también de resolver las disfunciones organizativas originadas en esos procesos irregulares de contratación de personal laboral, eso no supone en ningún caso que manifestemos una oposición al reconocimiento de relaciones jurídico laborales en la administración pública ${ }^{52}$, al contrario, pero lo que sí opinamos es que

\footnotetext{
51 Véase, M. SÁncheZ Morón, op. cit. «Derecho .....», p. 50 y ss.

52 Véase, J. Fondevila Antolin, op. cit. «Constitución y Empleo Público...», pp. 121 y ss.
} 
es necesario con carácter básico fijar claramente los elementos delimitadores que permitan establecer en que supuestos la relación jurídica tiene que ser de un tipo u otro, a este respecto ya formulamos en su momento la propuesta de la incorporación de la que denominamos «escala de servicialidad $\rangle^{53}$, a lo anterior debemos añadir que los procesos negociadores en el ámbito laboral han dado origen en muchos casos a Convenios Colectivos donde elementos como la promoción de la carrera profesional, régimen disciplinario, etc. son casi una copia de la actual regulación funcionarial, por lo tanto, entendemos que existen argumentos suficiente para sostener la necesidad de mantener el actual alcance del contenido de lo básico siendo insuficiente el aportado en el documento.

Ahora, de acuerdo con lo que habíamos indicado al inicio procedemos al examen de las argumentaciones jurídicas aportadas por la Comisión, así, la única argumentación propiamente jurídica que el informe recoge se limita a formular unas breves reflexiones sobre la amplia capacidad de decisión del legislador en la materia, señalando expresamente:

«De otra parte, no es cuestión que pueda resolverse sin más mediante la aplicación de criterios jurídicos. El artículo 149.1.18 a la la Constitución reserva al Estado la competencia sobre las bases del régimen jurídico de los funcionarios, pero no especifica, como es lógico, hasta dónde han de llegar esas bases. El artículo 149.1.7 , por su parte, reserva al Estado la legislación laboral, sin excepción, aunque existe alguna legislación de naturaleza administrativa que se aplica en común, ya hoy, a funcionarios y personal laboral (acceso, incompatibilidades, etc.), legislación ésta que desborda ese título competencial y se integra en el del artículo 149.1.18.

En definitiva, el legislador estatal goza de una amplia capacidad de decisión para determinar lo que debe considerarse básico en esta materia, dentro de los límites constitucionales y de los Estatutos de Autonomía.

Según una opinión bastante extendida, que la Comisión comparte, la vigente legislación básica del Estado en materia de función pública es demasiado extensa y detallada. No sólo eso, sino que existe todavía hoy cierta confusión sobre el carácter básico o no de algunas normas legales preconstitucionales, tal como se deduce de la jurisprudencia constitucional reciente (SSTC 37/2002 y 1/2003, entre otras).

Pues bien, parece que la comisión opta claramente por una alteración del actual alcance y contenido de lo básico en esta materia procediendo a su reducción, y de forma inicial dado que la Constitución no reconoce expresamente la inalterabilidad de lo básico y el órgano encargado de

53 Véase, Ibid.., pp. 125 y ss. 
aprobar la modificación legislativa cuenta con legitimación adecuada puede parecer inicialmente adecuada y correcta la propuesta, pero esta apariencia a nuestro entender no es consistente y un más profundo examen de la cuestión nos llevara a una respuesta muy diferente.

Así, no podemos desconocer las posiciones doctrinales y en especial de MoriLlo al que nos hemos referido anteriormente, que coinciden todos ellos en destacar la posibilidad de modificación del alcance de las bases e igualmente también se ha pronunciado el Tribunal Constitucional en la STC 99/1987, al señalar: «...es claro que la nota de estabilidad y generalidad de las normas básicas no es tampoco una exigencia absoluta, sino dependiente de la materia o del sector social al que afecte, de las circunstancias operantes en el caso y de los objetivos perseguidos, cuyos criterios de elección y oportunidad no pueden discutirse al legislador», pero también es cierto que el debate siempre se ha situado en torno a la posibilidad de ampliación del contenido de las bases pero no en cuanto a su reducción, con lo cual las primeras conclusiones deben ser tomadas, al menos inicialmente, con cautela. Debemos así recordar lo ya afirmado por el propio MoRILLO ${ }^{54}$, en el sentido de que la definición de lo que es básico o no, es un ámbito cerrado sobre las materias consideradas básicas y aunque exista un margen discrecional de decisión política, este nunca podrá superar o alterar ese límite, pues lo que no podría admitirse es que el legislador básico modificase sin límite alguno sus criterios sobre lo básico ampliando o reduciendo el ámbito del mismo, y esta es precisamente una de las primeras consideraciones a tener en cuenta sobre la inicial conclusión del Informe sobre el Estatuto Básico, pues efectivamente siempre existe un propio límite interno o núcleo de lo básico que nadie puede olvidar ni tampoco disponer, por eso el propio MORILLO ${ }^{55}$ reconoce que si bien, «la concreción de la articulación competencial es, en primer lugar, política en el sentido recogido por ARAGÓN REYES ${ }^{56}$, sea preciso -y esa es, a estos efectos, la labor del TC-llevar a la conciencia de los actores políticos la certidumbre de lo que, en términos constitucionales, pueden hacer, asi como la de lo que no pueden hacer; para que puedan prever en términos constitucionales los resultados-constitucionales- de sus actuaciones». Alcanzado este punto debemos preguntarnos que mecanismo podemos utilizar para fijar ese límite de lo básico, y a esta pregunta nos responde el propio autor ${ }^{57}$ al afirmar que estaríamos en

\footnotetext{
54 Véase, J. García Morillo, op. cit. «La versatilidad de lo ....», pp. 131.

55 Véase, J. García Morillo, op. cit. «La versatilidad de lo ....», pp. 137.

56 Véase, M. Aragón ReYes, «Constitución y Democracia», Edit., Madrid 1989, p. 119 y ss.

57 Véase, J. García Morillo, op. cit. «La versatilidad de lo ....», pp. 133.
} 
presencia de una delimitación definitiva de lo básico en cualquier ámbito material en el caso de un pronunciamiento expreso del Tribunal Constitucional, lo cual supone que ya no existe esa alegada libertad sin límite de modificación del alcance y contenido de las bases sino que ya podemos hablar de la existencia de una rigidez material en un supuesto concreto.

Pero ahora, debemos examinar otra cuestión que complementa lo anteriormente expuesto, en concreto, la pregunta de sí es posible una renuncia expresa o tácita por parte del legislador básico a regular un ámbito material cuyo contenido le corresponde de conformidad con el reparto competencial reconocido por la Constitución y así declarado expresamente por el propio Tribunal Constitucional, la respuesta a nuestro entender debe ser negativa, y ello, con independencia de lo ya expuesto por las siguientes razones: es preciso para un correcto enfoque del tema hacer un resumen de la doctrina constitucional sobre la construcción jurídica de los órganos del Estado y la correspondiente atribución de competencias a los mismos, las primeras aproximaciones al tema fueron formuladas ALBRECHT, OTTO GIERKE y GEORG MEYER, de todos ellos podemos extraer la consideración de que los órganos estatales constituyen la estructura del Estado-aparato y parte del Estado-comunidad. A través de ellos se formulan los programas políticos, se realizan las exigencias de la comunidad; se crean las normas; se vigila su aplicación; se instituyen derechos; se mantienen relaciones con otros Estados, es decir, se regula y ejercita toda la vida organizada de la comunidad. Así, como señala CERETI ${ }^{58}$ cuando se consideró al Estado como una realidad jurídica que mediante su propia organización puede aceptar como propias la voluntad y actividad de las personas físicas al frente de sus «oficios o conjunto de competencias», abandonándose de esta manera las tesis de la representación voluntaria para pasar a la de organicidad.

Como ya es sabido, esta concepción del Estado supone que este al ser considerado persona jurídica, actué por medio de órganos que inserta como parte integrante de su estructura. Así se puede afirmar que existe un solo sujeto, el Estado persona jurídica, integrando asimismo en los órganos la distribución de competencias. Así, los órganos forman, manifiestan y actúan directamente la voluntad y la potestad del Estado, hacen valer sus derechos, actúan para alcanzar sus fines, no como representantes, sino como instrumentos del mismo Estado, integrando un todo del cual los órganos son puntos delimitados que se distinguen por la diversidad de las competencias atribuidas.

Dado el primer paso en esta evolución jurídica, procede ahora el examen de las posiciones doctrinales en torno al ámbito o concepto de los

58 Véase, C. Cereti, «Corso di Diritto Costituzionale», Edit. U.T.E.T., Torino 1953, pp. 56 y 57. 
órganos estatales y su relación con la cuestión de la atribución competencial, así, como ya hemos anticipado en el concepto de órgano entran las personas físicas, pero también y en especial el oficio o conjunto de competencias, lo que ha denominado $K R \ddot{U} G E R^{59}$, «competencia instituida» y los medios materiales asignados al mismo. Pero tras esta primera y clásica aproximación al tema debe tenerse en cuenta la posición de Alessi $^{60}$ que define la competencia como el conjunto de funciones atribuidas al oficio, presentándose esta como una medida de cualidad. Posteriormente siguiendo la línea marcada por Foderato ${ }^{61}$ que rechazó la inclusión de las personas físicas titulares del oficio en el concepto de órgano, por entender que solo el «oficio-competencia» puede considerar órgano del Estado, al ser este el único que permite la identificación con el Estado.

Así, es Biscaretti Di Ruffia ${ }^{62}$ quien señala que la voluntad que manifiesta el órgano no debe considerarse propia de su titular, puesto que se imputa al órgano en su aspecto de institución y, por lo tanto, al Estado, porque si bien el órgano se individualiza frente a los otros órganos no se contrapone al Estado, se identifica con él.

Como consecuencia de lo anterior podemos afirmar que los órganos estatales carecen de personalidad jurídica, ya que esta solo corresponde al Estado, de forma que todas las cuestiones jurídicas suscitadas con los órganos son competencias nacidas de un solo sujeto de derecho, es decir, son cuestiones de Derecho objetivo, como ya expusiera en su momento Jellinek $k^{63}$.

Por último, y siguiendo a Burdeau ${ }^{64}$ se puede afirmar que el órgano no se identifica con las personas físicas titulares, se trata de un término impersonal que contempla sólo la organización estatal y coloca en un plano secundario a los individuos, señalando igualmente el autor que el valor y las aptitudes personales de los hombres que sirven a los órganos del Estado tiene una gran importancia desde el punto de vista político,

\footnotetext{
59 Véase, H. KRÜGER, «Allgemeine Staatslehre, W. Kolhammer», Edit. Verlag, Sttutgart 1964, p. 256.

60 Véase, R. Alessi, «Instituciones del Derecho Administrativo», Edit. Bosch, Barcelona 1970, p. 103.

61 Véase, S. Foderato, «Mannuale di Diritto Pubblico», Edit. Cedam, Padova 1971, pp.72 y ss.

62 Véase, BiscaretTI Di RufFIA, «Derecho Constitucional», Edit. Tecnos, Madrid 1987, p. XXXX.

63 Véase, G. JellineK, «Teoría General del Estado», Edit. Comares, Granada 2000, pp. 174.

64 Véase, G. Burdeau, «Traité de Science Politique», Edit. Librairie Genérale de Droit et de Jurisprudence», Vol. III, Paris, 1949, pp. 161 y ss.
} 
pero desde la óptica jurídica los individuos son indiferentes. Así, entiende que la cualidad de órgano legislativo no ha de reconocerse a cada diputado en particular, el órgano legislativo es el Parlamento considerado en conjunto, se trata por ello de un órgano colegiado (tal como ocurre con nuestra Constitución Española), así como señala Lucas Verdú ${ }^{65}$ de este carácter de impersonalidad podemos extraer la siguiente conclusión: la multiplicidad de los órganos constitucionales el Estado supone la incorporación de una nota básica al ejercicio de su función, y esta es la irrenunciabilidad de sus competencias puesto que estas no les pertenece más que en la medida y condiciones fijadas por la Constitución.

Lo que la doctrina clásica ha manifestado con relación a la naturaleza y configuración de ejercicio de la competencia por los órganos del Estado, es perfectamente trasladable a nuestro orden constitucional de manera que el Parlamento Estatal tiene atribuidas una serie de competencias por decisión expresa de la propia Constitución y su ejercicio en lo esencial aparece igualmente regulado por la misma norma y el juego combinado de diferentes referentes normativos destacando en el presente caso las previsiones de los artículos 148 y $149 \mathrm{CE}$, no existiendo a nuestro parecer duda alguna sobre la configuración jurídica del concepto «competencia», de acuerdo con las citadas previsiones, y así, recordemos siguiendo a TORNOS ${ }^{66}$, que procede establecer una distinción entre la «materia» configurada por los diferentes sectores sobre los que se proyecta la actuación de los poderes tanto del Estado como de las Comunidades Autónomas y por otro lado, la que podemos denominar propiamente "competencia» que supone la existencia de una potestad jurídica de actuación que se encuentra atribuida a cada tipo de organización (Estado o Comunidad Autónoma) sobre aquellas áreas o sectores materiales, es decir, nos referimos al ya expuesto concepto de materia. Así, de este concepto de competencia podemos predicar igualmente la posibilidad de establecer dos tipos de funciones posibles, a saber, la normativa (Legislativa y reglamentaria) y la de ejecución o gestión.

Por lo tanto, la competencia atribuida al legislador básico estatal cumple los requisitos legales de su configuración y atribución en derecho, dado que la misma nace por decisión constitucional recogida en las previsiones de los artículos 149.1.18, 103.1 y 3 y 149.1.1, lo que supone que de acuerdo con lo anteriormente expuesto la misma presenta el carácter intrínseco de la irrenunciabilidad de la misma, salvo previsión diferente

\footnotetext{
65 Véase, P. Lucas Verdú, «Curso de Derecho Político», Edit. Tecnos, Madrid 1977, p. 171.

66 Véase, J. Tornos MAs, op. cit. en la obra VV.AA. «Manual de Dret Public de .....», p. 199 y ss.
} 
en el propio texto constitucional como norma atributiva, y en nuestro caso el único supuesto que entendemos podría modular parcialmente esta situación lo encontraríamos en las previsiones del artículo $150.2 \mathrm{CE}$, o bien, la alternativa de una modificación del texto constitucional o la reforma de los Estatutos de Autonomía aunque esta última con todas las reservas al respecto, ya que debemos recordar lo que ya expusimos en apartados anteriores sobre la opinión manifestada en el informe emitido por el Instituto de Estudios Autonómicos, con relación a la posible reforma del Estatuto de Autonomía de Cataluña, y todo ello, sin olvidar que todas estas cuestiones no son más que posibles alternativas políticas de las que se desconoce su final y por ende, entendemos no pueden servir como punto de referencia para un adecuado análisis jurídico de la situación actual que es la que nos sirve de soporte para el debate sobre el futuro Estatuto del Empleado Público.

A la vista de todo lo expuesto, debemos volver sobre la pregunta inicial para confirmar la respuesta adelantada, que como recordamos era negativa, sobre sí era posible una renuncia expresa o tácita por parte del legislador básico a regular un ámbito material, cuyo contenido le corresponde de conformidad con el reparto competencial, reconocido por la propia Constitución y así declarado expresamente por el propio Tribunal Constitucional, y a la vista de esta respuesta podemos formular las siguientes conclusiones:

A) No existe duda alguna de la existencia de una atribución competencial al legislador básico estatal para la regulación de un Estatuto Básico del Empleo Público o de la Función Pública, en sentido más estricto desde una perspectiva constitucional, que nace del derecho objetivo, es decir, de las previsiones establecidas en la Constitución. Esa atribución competencial tiene una configuración legal que alcanza tanto la delimitación de la potestad jurídica de actuación como el ámbito material sobre el que recae la misma al amparo de las previsiones de los artículos 149.1.1; 149.1.18 y 103. 1 y 3 CE., y solamente la constitución puede modificar la competencia e igualmente las formas en que esta pueda ser objeto de transferencia o delegación, dado que la competencia por principio general tiene el carácter de irrenunciable.

B) Dado que la competencia, en sentido estricto, queda reservada su definición a la atribución de una potestad jurídica se puede argumentar de contrario que la propuesta de un estatuto de mínimos para nada incide sobre la propia naturaleza de la competencia, pero es en este punto, donde se debe añadir a lo expuesto, la cuestión de la «materia» sobre la que actúa la potestad jurídica de la 
competencia de forma que solo desde una perspectiva conjunta se puede comprender la totalidad del problema planteado, ya que estamos en presencia de un Estado descentralizado donde la proyección de la competencia sobre la materia constituye el eje clave del reparto competencial entre el Estado y las Comunidades Autónomas de conformidad con las previsiones de los artículos 148 y 149 CE.

C) $\mathrm{Y}$ es en este punto donde entra en juego lo examinado sobre la variabilidad del alcance y contenido de lo básico, y en concreto, sobre la posibilidad de la reducción de las bases consolidadas y vigentes. Así, debemos recordar que la definición de lo que es básico o no, es un ámbito cerrado sobre las materias consideradas básicas y aunque exista un margen discrecional de decisión política, este nunca podrá superar o alterar ese límite, pues lo que no podría admitirse es que el legislador básico modificase sin límite alguno sus criterios sobre lo básico ampliando o reduciendo el ámbito del mismo, es decir, existe un mínimo común uniforme o núcleo de lo básico sobre el que no es posible disponer ( irrenunciabilidad de la competencia), lo que no supone cercenar en ningún caso los ámbitos de decisión de los legisladores dado que ellos mismos se encuentran sometidos a los límites que la propia Constitución impone, salvo que este proceda a acordar la modificación de la norma fundamental.

Asimismo, no existe duda con respecto a que el pronunciamiento expreso del Tribunal Constitucional al examinar el alcance y contenido de unas bases supone una delimitación definitiva, al menos en la fijación del «mínimo común uniforme» en que se constituye esa legislación básica. Por lo tanto, estaría vedado al legislador estatal una regulación de lo básico cuyo alcance y contenido fuera inferior al existente dado que entonces estaríamos en presencia de un proceso de renuncia a la competencia constitucionalmente atribuida.

D) Así pues, debemos preguntarnos si el Tribunal Constitucional se ha pronunciado con relación al alcance y contenido de lo básico en referencia al Estatuto de la Función Pública, y la respuesta debe ser afirmativa, de forma que debemos remitirnos a lo ya expuesto al respecto en el apartado cuarto de este trabajo donde hemos constatado que a través de múltiples pronunciamientos ${ }^{67}$ ese Alto Tribunal ha declarado que la actual legislación básica postconstitucio-

${ }^{67}$ En concreto nos referimos a las SsTC 37/1981 ( f.j.5); 99/1987 f.j. 3 c); 37/2002 F.J. 8; 178/1989 F.J. 6; 63/1986; 96/1990 f.j. 3. 
nal ${ }^{68}$ supone una regulación completa e innovadora de las bases del régimen estatutario de los funcionarios públicos, sin descartar incluso la posibilidad de ampliar su contenido.

Por lo tanto, no se puede negar que ya existe un «mínimo común uniforme o núcleo esencial» de lo básico reconocido expresamente por el máximo órgano encargado de interpretar la Constitución, y por ello, estos contenidos regulados por el actual marco normativo deben necesariamente considerarse una delimitación definitiva de lo básico, por lo que toda actuación del legislador reduciendo el alcance y contenido de lo básico debe ser calificado de inconstitucional, en tanto en cuanto el actual marco jurídico constitucional no sufra modificación, y ello, con independencia de las posibles reformas estatutarias autonómicas que en este ámbito es muy dudoso que pueda plantearse una modificación del actual alcance de lo básico sin una reforma de la propia Constitución, como algunos expertos han constatado al estudiar una concreta reforma autonómica ${ }^{69}$.

Por último, y como conclusión final para una correcta exposición de nuestra propuesta resulta determinante tener en cuenta que la Administración en el sentido de totalidad o conjunto tiene a su vez un Estatuto constitucional único, conformado por los principios recogidos en el artículo 103.1 de la CE, y ello sin perjuicio de la heterogeneidad de su actividad y las lógicas consecuencias en sus diferentes regímenes jurídicos, y a su vez el Estatuto de la Función Pública en lógica correspondencia debe tener un contenido común a todos los servidores públicos y a partir de este punto podrán formularse las necesarias adaptaciones a las concretas actividades administrativas, como destaca PAREJO ${ }^{70}$. Efectivamente debemos considerar que el papel de la Administración es único, y deriva directamente de la Constitución Española y se proyecta sobre toda la actividad administrativa, de tal modo que ésta se constituye en un instrumento con respecto a la finalidad de lograr realizar el interés general en los términos recogidos por el derecho y bajo la dirección correspondiente del órgano de gobierno legítimamente constituido. Precisamente la consecución de la finalidad anteriormente señalada, como indicamos en otro trabajo ${ }^{71}$, tiene

\footnotetext{
${ }^{68}$ Así, lo concreta el Tribunal Constitucional en su STC 37/2002 f.j. 9, que se remite a las Leyes 30/1984 de 30 de Agosto; 53/1984, de 26 de diciembre y 9/1987, de 12 de Junio.

${ }^{69}$ En concreto nos referimos al «Estudio sobre la Reforma del Estatuto «Julio 2003, elaborado por el Instituto de Estudios Autonómicos, formando parte de la Comisión Académica los siguientes Profesores: Enoch Alberti, Enric Argullol, Joaquim Ferret y Carles Viver.

70 Véase, L. Parejo Alfonso, en el Prólogo al libro «Constitución y Empleo Público», Edit. Comares, Granada 2000 , p. XVII.

${ }^{71}$ Véase, J. Fondevila Antolin, op. cit. «Constitución y Empleo Público .......», pp. 84 y ss.
} 
su origen, desarrollo y concreción en el orden axiológico constitucional derivado de la cláusula del artículo 1.1 de la Constitución española, y por ello, surge la exorbitancia del régimen jurídico de la administración pública, que se transmite a todo los medios materiales, jurídicos y personales, de tal manera que nos encontramos ante un personal sometido a un «estatuto», distinto al resto de los trabajadores debido a su incorporación a la organización administrativa y también a su participación en el poder público, de esta manera se procede al reconocimiento constitucional de un estatuto de la función pública, que se configura como un instrumento necesario que asegura por un lado el equilibrio entre las condiciones de trabajo y por otro el dar cumplimiento a las exigencias del conjunto de la organización administrativa o Administraciones públicas, en plural, para que ésta pueda desarrollar adecuadamente su actividad, entendida en el sentido de asegurar el funcionamiento y continuidad de los servicios públicos, en un sentido amplio, (incluyendo tanto la actividad de autoridad como la propiamente prestacional). Así pues, la Administración Pública por su carácter servicial con el objeto de dar cumplimiento al interés general tiene necesariamente que asegurar la continuidad y permanencia del servicio público, en sentido amplio, en los términos fijados por el derecho, con subordinación a la dirección del gobierno y con un resultado eficaz en la consecución de ese interés general cual es la prestación de los servicios.

Por otro lado, al examinar la cláusula «Estado Social y Democrático de Derecho», y su conexión con la administración pública, queda acreditada la existencia de unos principios organizativos que solamente pueden ser interpretados y desarrollados conforme al citado orden axiológico, resultante de la conexión del articulo 1.1, con el artículo 10.1 de la Constitución Española, principios que se constituyen en parámetro y basamento de la actuación de la administración, ya que a lo que nadie presenta objeción es a la necesidad y exigencia de una actuación de la Administración (en los términos ya expuestos), y por lo tanto, esta tiene que realizarse en la forma y los términos previstos por el artículo 1.1, en conexión con el artículo 103.1, pues solo así será posible conseguir la necesaria continuidad y calidad de los Servicios Públicos, en sentido amplio, ahora bien, a este respecto destacamos la justificación que desde el orden axiológico constitucional ha realizado PAREJo Alfonso ${ }^{72}$, es

\footnotetext{
72 Véase, L. PAREJo Alfonso, op. cit. «Administración y Función.....», p. 79, y del mismo autor «Eficacia y Administración, tres estudios», MAP, 1995, p. 125 y ss., también A. PaLOMAR OlmEDA, «El Derecho de la Función Pública», Edit. Dykinson, Madrid 2003 p. 78 y ss., este autor centra su explicación exclusivamente en la garantía de la continuidad y calidad de los Servicios públicos.
} 
decir, solo los servicios pueden quedar asegurados a través de una actuación que de cumplimiento a la satisfacción del interés general de una manera eficaz (única posible), además la actuación deberá ser profesional, y asimismo, debe quedar garantizada que la actuación es conforme a Derecho y bajo la dirección del órgano de gobierno legítimamente constituido. Así pues, estos mandatos constitucionales derivados de la conexión del artículo 1.1. de la Constitución Española, con el artículo 103.1, del mismo cuerpo legal, que hemos denominado siguiendo a Parejo «Estatuto Constitucional Único de la Administración», nos han fijado una serie de principios organizativos que extienden de manera cohonestada sus previsiones sobre la configuración del Estatuto del Empleo Público, lógicamente debemos cuestionarnos en este momento como se han trasladado al ámbito de los medios personales, las previsiones axiológicas constitucionales de la Cláusula del artículo 1.1., en relación con el artículo 103.1, pues bien, debemos remitirnos nuevamente a nuestro trabajo al que ya nos hemos referido anteriormente, por lo cual resumiremos la cuestión, así, recordemos como los principios de Jerarquía y Objetividad (103.1) en su conexión con el Estado Democrático incide directamente sobre la configuración del contenido del régimen jurídico de los medios personales al servicio de la Administración Pública, así, en cuanto al primero de los principios, este despliega su eficacia en torno al denominado «estatuto personal» de los agentes públicos y su actuación y también sobre el «estatuto funcional», por ello, observamos como en el primer caso, la cuestión queda reconducida a la regulación del ejercicio de las funciones a desempeñar con relación a la existencia de un poder genérico de dirección, elemento clave en toda organización cuya finalidad es la de obtener la satisfacción eficaz de los intereses generales, y en cuanto al segundo estatuto, este principio también se proyecta, si bien con una diferente escala de intensidad sobre las diversas configuraciones de funcionarios públicos, por otro lado, el segundo de los principios, es decir, el principio de objetividad, se presenta como elemento clave en la configuración de la profesionalidad de los empleados públicos en el desarrollo de su actuación, que ampara el desarrollo de una serie de elementos esenciales en las relaciones jurídicas de estos, y en concreto, de los funcionarios públicos, cuales son el régimen de incompatibilidades, los principios de mérito y capacidad para el acceso a la función pública, el desarrollo de su carrera administrativa y la estabilidad en el empleo, pero a su vez destacamos igualmente como estos principios no actúan de manera exclusiva y excluyente en relación con el principio de Eficacia, de tal manera que este último se convierte en la clave que nos va a permitir dar una explicación tanto al modelo de régimen de empleo público por el que ha optado la Constitución Española, como a los contenidos de 
la relación jurídica de la totalidad de empleados públicos y, en especial de los funcionarios públicos.

Efectivamente, tanto la Doctrina ${ }^{73}$ como la Jurisprudencia del Tribunal Constitucional (STC 178/1989, 42/1990 entre otras), han destacado el papel esencial que este principio de eficacia tiene en materia de medios personales, por lo cual procede que realicemos una breve aproximación a la cuestión, así se ha expuesto en el propio informe, tal como hemos señalado anteriormente, el uso de la posibilidad de optar por fórmulas más cercanas al Derecho Privado justificando la decisión en la consecución de una mayor "eficiencia $\rangle^{74}$, no reiteramos comentario alguno sobre la cuestión pues entendemos que ha sido sobradamente analizada, pero de modo somero debemos indicar que nos movemos en conceptos diferentes, ya que el principio de «eficacia» cuenta con sustantividad propia, pues esta aparece regulada en la parte organizativa de la Constitución y para el establecimiento del Estatuto subjetivo de la Administración y la "Eficiencia» se predica del contexto de la ordenación de los recursos económicos públicos.

Pues bien, es el Principio de Eficacia y no la «Eficiencia», el soporte explicativo de la opción constitucional, ya que debemos tener en cuenta que, tal como hemos señalado repetidamente, en la Administración la organización y la actividad administrativa son instrumentos con relación a la finalidad a alcanzar, cual es la realización del interés general en los términos previamente definidos en el Derecho y con subordinación en la dirección del Poder público Ejecutivo, estas previsiones derivadas de la cláusula del articulo 1.1 C.E., nos aporta la explicación y justificación del por que la Administración tiene un régimen jurídico de naturaleza exorbitante y singular que se extiende lógicamente a su función pública ${ }^{75}$, de forma que la segunda representa en su conjunto el elemento personal de la primera.

\footnotetext{
73 Véase, L. PAREJo Alonso, «La Eficacia como principio jurídico de la actuación de la Administración Pública» DA. n. ${ }^{\circ}$ 218-219, 1989 , p. 47, del mismo autor, op. cit. «Administración y .......» p. 79 y ss.; asimismo L. MARTín REBOLLO, «La función pública Local de cara a su reforma» REVL n. ${ }^{\circ} 223-1984$, p. 233 y ss., del mismo autor, op. cit. «Constitución, Derecho Administrativo y Estado Autonómico», Publicaciones Asamblea Regional de Cantabria, Santander 1989, p. 44 y ss, y por último R. JIMÉNEZ ASENSIO, «Selección, formación y carrera administrativa en la función pública vasca: normación básica y situación actual», $D A$. n. ${ }^{\circ}$ 204-1985, p. 67 y ss.

74 Véase, Prats I J. CATAla, «Los fundamentos institucionales del sistema de mérito: la obligada distinción entre función pública y empleo público», DA. n. ${ }^{\circ} 241-242,1995$, p. 39 y ss.

75 Véase, L. PAREJO Alfonso, op. cit. «Administración y ») 80 y asimismo L.M. ArRoyo YANES, «La carrera administrativa de los funcionarios públicos», Tirant lo Blanch, Valencia ,1994, p. 138 y ss.
} 
Así, la actuación de la administración de acuerdo con las anteriores consideraciones lleva consigo la coordinación de las previsiones del artículo 1.1. $\mathrm{CE}$, con el artículo 103.1 CE, y por ello, la aparición de unas exigencias para los medios personales, cuales serian su actuación bajo los mandatos de los principios de Jerarquía, Objetividad y Eficacia, lo que conllevaría que nos encontremos con unos empleados públicos que actúan con total y absoluta «Profesionalidad», en el desarrollo de sus tareas y funciones con relación a los Servicios Públicos, en sentido amplio, de tal modo que quede garantizada su continuidad y calidad, por ello, es precisamente la opción constitucional a favor de un régimen Estatutario y el establecimiento o regulación de Estatuto de la Función Pública, con carácter general aunque no exclusivo, ya que la concepción de nuestra Constitución, al amparo del artículo 1.1.CE, es más amplia a nuestro entender como ya hemos expuesto en otras ocasiones.

Tal como hemos explicado en apartados anteriores, se constituyen en elementos claves de la relación jurídica de los empleados públicos como consecuencia de la proyección de los principios anteriormente reseñados: el Régimen de Incompatibilidades, Acceso al Empleo Publico y su estabilidad, el desarrollo de una Carrera Administrativa bajo criterios Objetivos (Principios de Igualdad, Mérito y Capacidad), y no por orientaciones exclusivamente políticas cuando no arbitrarias, y por último, la necesaria modulación del ejercicio de ciertos Derechos Políticos y Sociales reconocidos constitucionalmente, cuya justificación solamente puede encontrarse por el juego de la búsqueda de una eficaz prestación de los servicios públicos que garantice su continuidad y calidad bajo la dirección legitima del Gobierno, de tal modo que nos encontramos ante un necesario equilibrio entre el Estado Democrático y el Estado Social, de manera que dependiendo de los bienes jurídicos a tutelar por mandato constitucional prevalece uno u otro contenido de los dos tipos de estado señalados.

Por otro lado, al quedar acreditado que el reconocimiento constitucional del Estatuto de la Función Pública es claro, y se constituye por tanto en garantía para que la Administración pueda dar cumplimiento a los fines que tiene asignados el Estado, supone que nos encontramos ante un elemento esencial en la construcción de este, por ello, ha señalado claramente la Doctrina $^{76}$ que la función pública se encuentra protegida por una «garantía institucional», entendida ésta en el sentido reconocido por el derecho alemán, a través de $C$. SCHMITT, que supone el intento de asegurar la existencia de una

\footnotetext{
76 Véase, Ma .J. MONTORO CHINER, «El marco Jurídico constitucional sobre el acceso a los empleos públicos», en AA.VV., dentro de la obra «Situación actual y tendencias de la Función Pública Española», Comares, Granada, 1998, y en la misma obra colectiva , F. CASTILlO BLANCO, en la Presentación de la misma, y por último L.M. ARroYo YANES, op. cit. «La carrera administrativa .....», p. 169.
} 
serie de instituciones que se consideran consustanciales al Estado y que son recogidas por la propia constitución. De todo lo dicho, debemos concluir que como consecuencia del papel estructurador del principio de Eficacia en la Administración, pues solo desde esta opción es posible comprender el papel que desempeña los otros principios colaboradores, cuales son el de Objetividad y Jerarquía, y que permite entender el porque de la existencia en un marco democrático de ciertos condicionantes en la fijación de las relaciones de empleo, en una palabra el establecimiento de las condiciones que van a afectar al diario transcurrir de la vida de un funcionario y también las razones que amparan la existencia de limitaciones al ejercicio de Derechos Constitucionales, que en principio bajo la condición de ciudadano, no solo no podrían ser restringidos sino que contarían con una especial tutela, y, por otro lado, al configurar nuestra Constitución a la Administración Pública como una organización instrumental y servicial para la consecución eficaz del interés público, aparece ineludiblemente conectada la exigencia de la prestación con carácter de continuidad y calidad de los servicios públicos, en sentido amplio, y sólo desde la regulación de un «Estatuto Básico de la Función Pública o de los Empleados Públicos» puede tener acomodo una correcta y adecuada coordinación entre los principios organizativos, que son el soporte y guía de la actuación administrativa, con los medios personales que debe utilizar la administración pública para poder llevar a buen fin las diferentes previsiones constitucionales, y especial, el orden axiológico constitucional derivado del artículo 1.1. CE, en conexión con el 10.1. CE.

Finalmente, y retomando el inicio de esta conclusión donde afirmábamos que la administración era única debemos añadir como señala PAREJO ${ }^{77}$ que también «diversa», la unidad como ya hemos explicado ampliamente proviene del estatuto único constitucional (103.1.CE) de la totalidad de las Administraciones Públicas siendo el desarrollo de su régimen jurídico básico para todas ellas el constitucionalmente reconocido por el artículo 149.1.18 $\mathrm{CE}$, y asimismo, la diversidad tiene también su origen especialmente en la organización territorial del Estado y la subordinación a la dirección de cada gobierno autónomo y con el objeto de obtener un resultado eficaz en la consecución de ese interés general cual es la prestación de los servicios ${ }^{78}$. De

\footnotetext{
77 Véase, L. PARejo Alfonso, en el Prólogo a op. cit. «Constitución ....», p. XXI.

78 Véase, I. MARTínEZ DE PISON APARICIO, «Los Derechos no Económicos de los funcionarios, en especial el Derecho al Cargo», en la obra VV.AA. "Situación Actual y Tendencias de la función pública española», Edit. Comares, Granada 1998, p. 345, señalando expresamente: «La Constitución establece un conjunto de principios materiales desde los que son deducibles, de modo inmediato, un conjunto de derechos funcionariales elementales. Estos a su vez, son instrumentos necesarios para la realización de ese modelo constitucional de administración servicial (lo que exige profesionalidad en el funcionariado y retribución justa), objetiva (para lo que requiere la imparcialidad
} 
esta forma nos encontramos con la existencia por un lado de un Estatuto común y único de todas las Administraciones $(103.1 \mathrm{CE})$ que incide directamente en el de la Función Pública (103.3 CE), de manera que el alcance y contenido de las bases (149.1.18 CE) proviene directamente de las previsiones de estos estatutos directamente engarzados a su vez con el orden axiológico constitucional.

Cuestión diferente son las consideraciones que responden al ámbito de la política de personal utilizadas por la Comisión que, sí bien, a nuestro entender son al menos muy discutibles no pueden suponer en ningún caso fundamento jurídico suficiente para justificar la elaboración de un «estatuto» que reduzca el actual alcance y contenido de lo básico, ya que como hemos acreditado, el actual «mínimo común» es en estos momentos indisponible para el legislador básico salvo modificación constitucional.

\section{BREVES REFLEXIONES SOBRE ALGUNAS DE LAS PROPUESTAS CONTENIDAS EN EL INFORME}

Tras el examen del principal elemento de debate que suscita a nuestro entender las propuestas del Informe sobre el futuro «Estatuto de los Empleados Públicos», es decir, la reducción del alcance y contenido del futuro estatuto, dado que la decisión que se adopte al respecto lógicamente va a condicionar el desarrollo y regulación de aspectos sustanciales del mismo, vamos a realizar algunas consideraciones puntuales sobre algunas cuestiones examinadas en el citado informe que tienen una directa relación con el tema principal de este trabajo y con las cuales no compartimos las conclusiones formuladas al respecto, asimismo también consideramos que al citado informe se le debería incorporar una propuesta complementaria que expondremos al final de este epígrafe.

\section{A) La Carrera Administrativa y su necesaria regulación por el futuro Estatuto de los Empleados Públicos}

La carrera administrativa tanto en su vertiente horizontal como vertical, se constituye a nuestro entender, en la clave de bóveda de todo sistema de función pública, dado que está, junto con el régimen retributivo son los

del servicio público), con sometimiento pleno a la Ley y el Derecho...( así hay que establecer derechos a los funcionarios) .....desde una uniformidad mínima que permita, a la vista de los principios de unidad de actuación del Estado, cooperación y de eficacia». 
elementos centrales en los que ha de apoyarse cualquier organización, y ello supone, en primer lugar, como señala CÁDIZ DELEITO ${ }^{79}$ podamos definir la carrera como la ordenación de la trayectoria profesional de un individuo para adecuar sus intereses particulares al servicio de los fines y objetivos de la organización, de forma que elementos como la formación, ascensos, promoción, movilidad horizontal y retribuciones puedan suponer un atractivo y estímulo para la permanencia y una adecuada prestación de servicios, pronunciándose en este mismo sentido el $M A P^{80}$, entendiendo que la carrera constituía el instrumento adecuado para atraer y fomentar la permanencia de su personal, y en segundo lugar, en nuestra opinión, conseguir a través de la misma que las Administraciones Públicas puedan dar adecuado cumplimiento a los principios organizativos de su «Estatuto Común», en concreto, jerarquía, objetividad y eficacia para una consecución eficaz del interés público.

A pesar de la importancia que reviste la cuestión de la carrera administrativa, el informe entiende y así lo manifiesta en sus propuestas, que la misma no debe ser objeto de regulación por el futuro Estatuto de los Empleados Públicos, sino que esta cuestión quede absolutamente en mano de cada comunidad autónoma, de manera que el único objetivo del estatuto sería «...legitimar las opciones de los diferentes legisladores y administraciones puedan optar al respecto» ${ }^{81}$, ya que «...no debería imponerse obligatoriamente con carácter general y menos aún por un Estatuto Básico» ${ }^{82}$, es decir, el Informe propone al Estado que proceda a renunciar a su competencia sobre lo «básico», de manera que quede desregularizada toda la materia referida a la carrera administrativa.

Así, esta propuesta, ante la cual disentimos, de excluir del ámbito material del futuro Estatuto del Empleo Público la carrera ha tenido un cierto reconocimiento en algún sector doctrinal ${ }^{83}$, que sustentaba su posición

\footnotetext{
79 Véase, J.L. CAdia Deleito, «Notas sobre la Carrera Profesional del funcionario público», D.A. n. ${ }^{\circ} 210-211,1987$, p. 99.

80 Véase, el Informe «Reflexiones para la Modernización de la Administración del Estado», Edit., $M A P$, Madrid, 1990, p. 109 y ss.

81 Véase, «Informe de la Comisión para el estudio y preparación del estatuto básico del empleo público», MAP, Madrid, 2005, p. 99.

82 Véase, Ibid., p. 98.

83 Véase, R. PARAda VÁzQuez, «Constitución, Burocracia y Comunidades Autónomas», D.A. n. ${ }^{\circ}$ 182, pp. 67 a 96., asimismo, M. BAENA DEL ALCAZAR, «La función pública en la Constitución y en las Leyes Orgánicas», en la obra de VV.AA. «Administración y constitución. Estudios en homenaje al profesor Mesa Molés», Edit. Presidencia del Gobierno, Madrid 1982, p. 77 y ss. y, por último, ARroyo YANES, op. cit. «La Carrera.....», p. 163 y ss.
} 
fundamentalmente en la consideración de que la ubicación sistemático constitucional de la carrera administrativa se encuentra en el ámbito de la competencia de autoorganización de cada tipo de administración pública, entendiendo que el elemento organizativo queda fuera del campo objeto de regulación previsto por el artículo 149.1.18 CE.

Ahora bien, en contra de este criterio se manifiesta otro sector doctrinal FIGUERA I LLUCH Y TRAITER I JIMENEZ ${ }^{84}$, que sostienen que el Estado ostenta una plena competencia para regular los aspectos esenciales de la organización burocrática y que forma parte necesaria del régimen jurídico de la administración y por lo tanto del contenido básico del Estatuto; asimismo, también existen otras posiciones doctrinales ${ }^{85}$, alguna incluso de miembros de la comisión aunque con ciertas diferencias de argumentación, que sostienen la misma posición si bien su fundamento difiere, de forma que estos consideran a la carrera administrativa como un parte esencial y necesaria del Estatuto básico de la función pública, y ello, como lógica consecuencia del pronunciamiento expreso del Tribunal Constitucional sobre el contenido del Estatuto, en concreto todos ellos se refieren a la conocida STC 99/1987.

Por último, nos parece importante destacar lo manifestado por Fernández Farreres ${ }^{86}$ al afirmar que «el problema es lo que el Estatuto no dice», entiende que estamos en presencia de una norma de mínimos cuyo único

\footnotetext{
${ }^{84}$ Véase, M. Figuera I Lluch, op. cit. «La Conflictivitat......», pp. 33 y ss. y J.M. Trayter I JiMNEZ, «La Conflictivitat Competencial - Las Bases del .....», , pp. 14 y ss.

85 Véase, M. SÁNCHEZ MoRón, op. cit. «Derecho de.....», p. 66, donde el autor reclama como contenido del Estatuto los aspectos reconocidos por la STC 99/1987, que recordemos menciona expresamente la carrera administrativa, pero además el mismo autor se manifiesta e la misma manera en su artículo para el Diario EL PAIS, de 18 de Diciembre de 1997 , titulado «El Sistema del Botín», e igualmente en el mismo medio de comunicación ,reitera su posición en fecha 3 de Septiembre de 1998 , en el artículo «Del estatuto a la reforma de la función pública», Ahora bien, conviene destacar que este autor posteriormente en la obra VV.AA., «Situación actual y tendencias de la función pública española», el artículo «Nuevo marco jurídico y competencial del personal al servicio de las administraciones», Edit. Comares, Granada 1998, pp. 71 y ss. señala como áreas materiales que deben incorporarse al futuro Estatuto (subjetivo) de la función pública en lo estrictamente indispensable las normas «para regular las bases de la carrera administrativa (en la medida que exista) y la promoción profesional «, de todos modos lo que parece que no ofrece duda es que esta materia debe ser regulada al menos en lo esencial por un futuro Estatuto; igualmente I. MARTínEZ DE PISÓN APARICIO, «Los Derechos no Económicos de los funcionarios, en especial el Derecho al Cargo», en la obra VV.AA. «Situación Actual y Tendencias de la función pública española», Edit. Comares, Granada 1998, p. 346.

86 En concreto nos referimos su intervención el día 22 de Junio de 2005, en una mesa redonda «La perspectiva del Derecho Administrativo con respecto al Informe de la Comisión», celebrada en el marco del Seminario «Hacía un Estatuto Básico del Empleado Público», en la ciudad de Santander y organizado por la Universidad Internacional Menéndez Pelayo (UIMP) en colaboración con el INAP.
} 
objetivo es la desregulación de la materia. También destacó su disconformidad con la promoción profesional, entendida como carrera administrativa, ya que a su entender no soluciona nada y además olvida cuestiones tan importantes como la antigüedad y la proporcionalidad en la carrera (escalón o categoría), y todo ello, por la voluntad manifiesta de desregulación que ni entendía ni comprendía, añadiendo también, que como consecuencia de esa renuncia a regular esta materia la movilidad interadministrativa va a resultar imposible.

Igualmente, MALARET I GARCIA ${ }^{87}$, sostuvo la necesidad de un mayor desarrollo de la carrera administrativa, y por último, propuso, como lógica consecuencia de lo anterior, que la movilidad interadministrativa fuera lo más amplia y general posible.

A todo lo anterior debemos añadir que a nuestro entender, tal como ya hemos manifestado en apartados anteriores, es el Tribunal Constitucional el que se ha manifestado de forma más clara y expresa sobre el contenido de lo «básico» en el ámbito material de la función pública, y en concreto ha incluido la carrera administrativa dentro de ese contenido necesario, destacando los pronunciamientos de las SsTC 99/1987 y 37/2002 que ya han sido transcritos anteriormente, pero especialmente queremos llamar la atención sobre el contenido e la STC 385/1993, que señala:

«Desde una perspectiva también genérica conviene subrayar, ante todo, que el Estado cuenta aquí con una triple cobertura constitucional, ya que -por una parte- la competencia estatal sobre las bases del régimen estatutario de los funcionarios (art. 149.1.18. ${ }^{a} \mathrm{CE}$ ), todos ellos, cualesquiera que fuere la esfera de la Administración a la cual pertenezcan, comprende como propia la regulación de la carrera administrativa y sus aledaños, con carácter general o para grupos determinados...»

Así pues, entendemos que nadie puede negar a la vista de los pronunciamientos del Tribunal Constitucional que la "carrera administrativa», es parte obligada y necesaria del futuro Estatuto de los Empleados Públicos, y que el debate doctrinal al que nos hemos referido anteriormente debe quedar necesariamente cancelado, ante la claridad y contundencia de los «obiter dicta» reseñados.

A lo anterior, debemos añadir otro argumento propiciado por la STC 37/2002, que recordemos, declaraba como contenido estable y delimitado del Estatuto de la Función pública, la actual regulación contenida en la Ley 30/1984 de Medidas para la Reforma de la Función Pública, y si exa-

87 En este caso nos remitimos a su participación igualmente en la mesa redonda citada en nota anterior. 
minamos el contenido de la misma observaremos que la carrera administrativa aparece regulada con detalle en su articulado, otra cuestión es que el concreto modelo sea el más adecuado o no, y anticipamos nuestro rechazo al actual sistema y adhesión a los planteamientos de la Comisión sobre la carrera horizontal, de forma que esta se incorpora necesariamente como contenido del «mínimo común uniforme» en que se constituye la legislación básica dictada al amparo de las previsiones el artículo 149.1.18 y 103.3 CE.

Por último, en primer lugar, no debemos olvidar como manifestaba SÁNCHEZ MORÓN ${ }^{88}$, que la carrera administrativa se encuentra amparada por las previsiones del artículo 23.2 CE., lo que conecta lógicamente esta materia con las previsiones el artículo 149.1.1 CE, y por lo tanto, a nuestro entender la necesidad de incorporar su regulación al Estatuto Básico y en segundo lugar, y retomando unas conclusiones anteriores hay que tener en cuenta que la administración es única y también diversa, de forma que podemos hablar de un estatuto único constitucional (103.1.CE) de la totalidad de las Administraciones Públicas siendo el desarrollo de su régimen jurídico básico para todas ellas el constitucionalmente reconocido por el artículo 149.1.18 CE, y asimismo, la diversidad tiene su origen especialmente en la organización territorial del Estado, y esto supone que ese Estatuto común (103.1 CE) incide directamente en el de la Función Pública (103.3), y por ello, deben necesariamente tenerse en cuenta los principios organizativos del mismo, en concreto, Jerarquía, Objetividad y Eficacia que proyectan su contenido sobre la configuración jurídico legal de toda carrera administrativa, pues esta se constituye en el elemento clave para que el personal al servicio de las administraciones públicas pueda prestar sus servicios de forma adecuada y eficaz, pues si no existe una carrera conforme en su ordenación a la propia Constitución será imposible el cumplimiento de las funciones asignadas constitucionalmente a las administraciones públicas de acuerdo con lo previsto en el artículo 103.1 CE y al encontrarnos en el ámbito del Estatuto único, esta materia no puede quedar fuera del contenido de las bases (149.1.18).

\section{B) Las Retribuciones y la Carrera Administrativa}

A este respecto el informe de la Comisión responde a la lógica interna del mismo, es decir, la reducción del contenido de lo básico; así, lógica-

\footnotetext{
88 Véase, M. SÁNCHEZ Morón, op. cit. VV.AA., «Situación actual y tendencias de la función pública española», el artículo «Nuevo marco jurídico y competencial .....», p. 66.
} 
mente si entre las propuestas como veíamos anteriormente se rechaza la regulación de la carrera administrativa con carácter básico, en directa conexión con lo anterior el informe ${ }^{89}$ propone una cesión integral de las retribuciones complementarias a las Comunidades Autónomas, a lo que en principio nada habría que objetar, sino fuera porque a la vez manifiestan su voluntad de renuncia al establecimiento de un concepto retributivo común que este vinculado al desarrollo de la carrera administrativa, cuestión esta con la que debemos mostrar nuestra disconformidad, ya que si como hemos acreditado la carrera administrativa debe necesariamente formar parte del contenido de un futuro estatuto, también es preciso reformular la posibilidad de incorporar un concepto específico vinculado a la misma y que este sea por primera vez común a todos los funcionarios en su cuantía.

Así, como destaca CASTILLO BLANCO ${ }^{90}$ es unánime la opinión en torno a considerar que un adecuado sistema retributivo y en especial la aplicación, coordinada del mismo con la carrera administrativa supone la piedra angular de todo modelo de función pública y, podemos añadir que también constituye unos de los contenidos esenciales a incorporar al Estatuto de los empleados públicos.

Efectivamente, debemos coincidir con CASTILLO BLANCO ${ }^{91}$ en considerar que el establecimiento de unas retribuciones básicas, la estructura y cuantía de las mismas, así como la regulación y fijación de la cuantía también de los conceptos retributivos directamente relacionados con la carrera administrativa deben ser comunes a todos los funcionarios públicos. Esta consideración podemos fundamentarla, en primer lugar, en la necesidad de facilitar la movilidad interadministrativa ${ }^{92}$, en segundo lugar, las exigencias constitucionales de los principios de igualdad y solidaridad,

\footnotetext{
89 Véase, «Informe de la Comisión para el estudio y preparación del estatuto básico del empleo público», MAP, Madrid, 2005, p. 142.

${ }^{90}$ Véase, F. CASTillo Blanco, en la obra VV.AA., «Situación actual y tendencias de la función pública española», el artículo "Análisis del régimen Retributivo del personal al servicio de la administración pública: Situación Actual y Perspectivas», Edit. Comares, Granada 1998, p. 363. y en el mismo sentido M. SÁnCHEZ Morón, op. cit. «Derecho de la.....», p. 203.

91 Véase, F. Castillo Blanco, «El Sistema Retributivo en la Función Pública Española», Edit. Marcial Pons, Madrid 2002, p. 67.

92 Sobre esta cuestión se manifestó FERNÁNDEZ FARRERES en su intervención el día 22 de Junio de 2005 , en una mesa redonda «La perspectiva del Derecho Administrativo con respecto al Informe de la Comisión», celebrada en el marco del Seminario «Hacía un Estatuto Básico del Empleado Público», en la ciudad de Santander y organizado por la Universidad Internacional Menéndez Pelayo (UIMP) en colaboración con el INAP, señalando su preocupación porque la propuesta de regulación de las retribuciones en el Informe, a su entender suponía favorecer el que crezcan las diferencias retributivas entre todas las CCAA y con el propio Estado, y asimismo, perjudica seriamente la movilidad interadministrativa.
} 
como ha declarado expresamente la SsTC 385/1993 y 96/1990 (fund. jco. $3^{\circ}$ ) supone una adecuada justificación para reclamar este trato común, y en tercer lugar, porque ningún modelo de carrera se puede regular sin una directa normación de la respuesta retributiva al desarrollo y evolución de la misma, de manera que una desconexión a este respecto entraría en directa colisión con los principios organizativos básicos $(103.1 \mathrm{CE})$ de objetividad y eficacia, dado que sería imposible dar una adecuada respuesta a las exigencias de estos principios sin un adecuado sistema de carrera y retributivo asociado a la misma.

Por último, debemos indicar que la propuesta formulada en el presente trabajo de incorporación de un concepto retributivo vinculado al desarrollo de la carrera administrativa, con carácter básico y común a todos los funcionarios públicos, tanto en su definición como en la cuantía, y como lógica consecuencia su incorporación al concepto consolidado de "retribuciones básicas», no es nueva, ya que CASTILLO BLANCO ${ }^{93}$ previamente a la elaboración del Informe de la Comisión propuso esta misma solución y también otros sectores ${ }^{94}$ han defendido la ampliación del contenido básico en la materia de retribuciones.

\section{C) La Plurianualidad en los Acuerdos y Pactos Saláriales}

Una de las situaciones más conflictivas que ha vivido en los últimos tiempos el empleo público, tuvo su origen en la decisión de desvincularse de los acuerdos plurianuales formalizados por el Gobierno del Estado por parte del siguiente Gobierno de diferente color político y que genero un conflicto que ha tenido sus últimos coletazos jurisdiccionales recientemente ${ }^{95}$, así, nos llama la atención que en el Informe de la Comisión ${ }^{96}$, no

\footnotetext{
93 Véase, F. Castillo Blanco, op. cit. «El Sistema Retributivo en la Función......», p. 68.

94 Intervención el día 22 de Junio de 2005, en una mesa redonda «La perspectiva del Derecho Administrativo con respecto al Informe de la Comisión», celebrada en el marco del Seminario «Hacía un Estatuto Básico del Empleado Público», L. MARTín ReBollo, en la que manifestó su discrepancia con el Informe proponiendo una ampliación de lo básico en la materia de retribuciones.
}

95 Nos estamos refiriendo al conflicto surgido por la declaración del Ministro de Administraciones Públicas con fecha 19 de Septiembre de 1996 señalando que no habría incrementos salariales para el año 1997, a pesar del pacto suscrito en el año 1994, la decisión fue impugnada ante el Tribunal Supremo, el cual desestimó la demanda por sentencia de fecha 21 de marzo de 2002, contra la misma se interpuso recurso de Amparo que ha sido inadmitido por Auto del TC de fecha 31 de Enero de 2005, por último, se ha interpuesto recurso ante el orden judicial europeo por posible violación del Derecho de libertad sindical y por ende el de negociación colectiva.

96 Véase, «Informe de la Comisión para el estudio y preparación del estatuto básico del empleo público», MAP, Madrid, 2005, p. 170. 
se haya propuesto una solución a esta cuestión, y al contrario, se afirme que en materia de incrementos retributivos la vigencia de los Acuerdos debe ser necesariamente anual, y ello, con fundamento en la aplicación del principio de anualidad presupuestaria, realmente esta conclusión no puede ser compartida, dado que no se nos aportan los criterios jurídicos utilizados para obviar las previsiones que la legislación general establece con relación a la plurianualidad, por el contrario entendemos que existen razones suficientes para sostener la tesis contraria y que a continuación procedemos a exponer.

Así, efectivamente el principio de anualidad encuentra su fundamento en el límite temporal de la autorización para ejecutar el gasto en los límites reconocidos en la correspondiente Ley de Presupuestos, de forma que mediante ella se habilita al Ejecutivo para gastar, pero imponiendo ciertas restricciones, en este caso de carácter temporal. El Principio de anualidad exige que se haga uso de la autorización legal para gastar durante el ejercicio presupuestario (del 1 de Enero al 31 de Diciembre de cada año), de forma tal que los créditos o la parte de ellos no utilizados se amortizan al concluir aquél.

Este principio aparece recogido expresamente en el artículo 134.2 CE, y que el Tribunal Constitucional ha considerado también de aplicación a las Comunidades Autónomas, por afectar a aspectos esenciales de la institución presupuestaria, a lo que hay que añadir que el artículo 21.1 de la LOFCA, no sólo resalta el carácter anual de los Presupuestos de las Autonomías, sino que establece igualmente que su vigencia se extenderá por el mismo periodo que los del Estado, y con ello lograr una mejor aplicación del principio de organización administrativa de coordinación, y a estas previsiones y en el mismo sentido debemos añadir lo previsto en la Ley 18/2001, General de Estabilidad Presupuestaria y la Ley 47/2003, General Presupuestaria.

Ahora bien, este principio de anualidad es objeto de alguna excepción, destacando a este respecto, los supuestos en que se apruebe un gasto que se deba pagar a lo largo de los ejercicios siguientes, siempre, lógicamente que la Ley de Presupuestos de cada uno de ellos apruebe el crédito para afrontar la parte del gasto correspondiente previamente comprometido para ejercicios posteriores, si bien, de forma inicial se argumentaba la necesidad de esa autorización anual, el reconocimiento del principio de anualidad se altera por la Ley 18/2001, General de Estabilidad Presupuestaria, que incorpora en su artículo $4^{\circ}$, el denominado "Principio de Plurianualidad», señalando expresamente: 
«La elaboración de los presupuestos en el sector público se enmarcará en un escenario plurianual compatible con el principio de anualidad por el que se rige la aprobación y ejecución presupuestaria.»

Esto supone que la autonomía posterior del legislador queda en cierto modo paliada por este principio, que supone la elaboración de escenarios de previsión plurianual vinculantes para el sector público, y en el mismo sentido se pronuncia el artículo 31 de la Ley 47/2003 General Presupuestaria.

Posteriormente, en la misma Ley 47/2003, General Presupuestaria se reconoce igualmente este principio en el artículo 26.1, que señala:

«La programación presupuestaria se regirá por los principios de estabilidad presupuestaria, plurianualidad, transparencia y eficiencia en la asignación y utilización de los recursos públicos, conforme a lo dispuesto en la Ley 18/2001, de 12 de diciembre, General de Estabilidad Presupuestaria.»

Procediendo en los artículos siguientes al desarrollo legal para la aplicación de esta previsión, y en especial en el artículo 29 c), que señala:

«6. Los programas plurianuales establecerán su contenido referido a los extremos siguientes:

c) Los medios económicos, materiales y personales necesarios con especificación de los créditos que, para el logro de los objetivos anuales que dichos programas establezcan, se propone poner a disposición de los centros gestores del gasto responsables de su ejecución».

Es decir, no sólo estamos en presencia de una institución presupuestaria consolidada y perfectamente acotada sino que además la misma también resulta de aplicación a las Comunidades Autónomas, y a este respecto debe tenerse en cuenta las previsiones de la Ley Orgánica 5/2001 complementaria de la Ley General de Estabilidad Presupuestaria que señala en su artículo $2^{\circ}$ lo siguiente:

«Los principios de estabilidad presupuestaria, plurianualidad, transparencia y eficiencia en la asignación y utilización de recursos públicos, tal como aparecen definidos en la Ley 18/2001, General de Estabilidad Presupuestaria, serán aplicables a las Comunidades Autónomas en la forma prevista en esta Ley Orgánica.»

Por lo tanto, no se alcanza a entender las razones que pueden haber servido de justificación a la Comisión para formular su propuesta, dado que como se pude observar el vigente marco jurídico presupuestario no presenta inconveniente alguno para que tanto por parte del Estado como de las Comunidades Autónomas se alcancen acuerdos cuyo objeto sean los compromisos económicos referidos al ámbito salarial, siendo diferida la ejecución de ese compromiso de forma anual hasta un plazo de 
REFLEXIONES EN TORNO AL INFORME PARA LA PREPARACIÓN DE UN ESTATUTO BÁSICO DEL EMPLEADO PÚBLICO...

cuatro años, además, debe tenerse en cuenta que ninguna de las normas examinadas establece la exclusión de la plurianualidad de los gastos de personal.

Por último, señalar que el reciente Proyecto de Ley de Agencias Estatales para la mejora de los servicios públicos ${ }^{97}$, reconoce igualmente en el artículo 10.2 en conexión con el artículo 13.2, la posibilidad de compromisos plurianuales incluyendo dentro de los mismos los gastos de personal.

97 Proyecto publicado en el Boletín oficial de las Cortes Generales (Sección A), de fecha 26 de Agosto de 2005. 


\section{Crónicas y Documentos}

